\title{
Neue oder wenig bekannte Coleoptera Longicornia.
}

\author{
17. \\ Von \\ CHR. AURIVILLIUS. \\ Mit 9 Figuren im Text. \\ Vorgelegt am 10 März 1920.
}

Cerambycidae.

523. Ophistomis splendida n. sp. - Angusta, elongata, nigra; prothorace (summo margine apicali nigro excepto), scutello et mesosterno rufis; elytris totis splendide cyaneis; antennarum articulis $9-11$ apiceque articuli $8 \mathrm{i}$ albidis; capite sparsim, in vertice dense punctato, fronte sulco medio longitudinali antice dilatato instructa et utrinque carinata; prothorace elongato-conico lateribus fere rectis, apice leviter constricto, ad basin profunde bisinuato, inaequaliter punctato linea dorsali laevi; elytris undique dense punctatis, brevissime nigro-setosis, apicem versus leviter angustatis, apice oblique leviter emarginato-truncatis angulo exteriore spinoso. Long. corporis $17 \mathrm{~mm}$.

Amazonas: Teffe. - Reichsmuseum in Stockholm.

Durch die Färbung, die metallglänzenden Flügeldecken und die Punktierung von übrigen mir bekannten Arten abweichend. Das einzige vorliegende Stück scheint ein Weibchen zu sein.

Arkiv för zoologi. Band 13. N:o 9. 
524. Oregostoma Iuridum KLUG. var. pallipes n. var. Statura majore, pedibus abdomineque totis testaceo-brunneis, elytris testaceis vitta postice dilatata utrinque valde abbreviata nigra, antennisque paullo longioribus medium elytrorum fere superantibus a forma typica differt. Long. corporis $16 \mathrm{~mm}$,

Brasilien: Parana. - Reichsmuseum i Stockholm. - P. Dúś́n.

Der schwarze Suturalfleck an der Wurzel der Flügeldecken sowie alle schwarzen Zeichnungen im letzten Drittel der Flügeldecken fehlen völlig. Der schwarze Längsstreif ist ausgezogen dreieckig, nach vorn stark verschmälert und von der Naht breit getrennt; er nimmt nur das zweite Drittel der Flügeldecken ein. Es liegt mir nur ein Stück vor und es ist darum nicht möglich zu entscheiden, ob wir es hier mit einer südlichen Rasse oder nur mit einer Aberration zu tun haben.

525. Oregostoma unicolor n. sp. - Unicolor, fuscobrunneum elytris basi excepta abdomineque pallidioribus, capite obscuriore, supra dense punctatum, nudum; carina media pronoti tenui, obtusa, parum distincta; scutello nigro leviter albido-pubescente; elytris parte tertia basali obscuriore, apicem versus sensim pallidioribus, apice truncatis inermibus; corpore infra nitido vel subnitido, sternis sparsim punctatis et plagiatim albo-pubescentibus; abdomine obsolete punctatis cingulis albo-tomentosis medio late interruptis $4-5$ ornato; antennis medium elytrorum attingentibus articulis 5-11 albosericeis et incrassatis. Long. corporis $11 \mathrm{~mm}$.

Brasilien (aus Sommers Sammlung). - Reichsmuseum in Stockholm.

Weicht von O. luridum nicht nur durch die Färbung und die Abwesenheit aller Zeichnungen, sondern auch durch die Punktierung der Flügeldecken ab. Bei $O$. unicolor sind die Flügeldecken an der Wurzel tief und sehr dicht punktiert, nach hinten aber werden die Punkte allmählig etwas kleiner; bei $O$. luridum aber sind die Punkte an der Wurzel schwächer als in der Mitte. Das Halsschild ist fast zylindrisch, etwas länger als breit, aber wenig schmäler als die Wurzel der Flügeldecken. 
526. Oregostoma fasciatum n. sp. - Nigrum, infra plagiatim albidotomentosum; elytrorum tertia parte basali fasciaque lata subapicali flavo-testaceis; capite dense rugosopunctato parum adpresse piloso; antennis medium elytrorum attingentibus vel paulo superantibus, nigris, articulis (4) $5-11$ pube argenteo-sericea vestitis; prothorace pilis brevibus adpressis albidis vel flavescentibus dense vestitis, supra maculis tribus elongatis nudis nigris rude punctatis in medio linea transversa conjunctis lineaque utrinque laterali longitudinali nigra ornato; elytris punctatis, apice truncatis, inermibus, saltem apicem segmenti $4^{\mathrm{i}}$ ventrali attingentibus; pedibus punctatis unicoloribus nigris; plaga magna postica metasterni et episternis metasterni nudis nigris; ventre cingulis 4 medio interruptis albido-hirsutis ornato. Long, 14-17 $\mathrm{mm}$.

Paraguay. - Reichsmuseum in Stockholm.

Von $O$. luridum weicht diese Art nicht nur durch Farbe und Zeichnung, sondern auch dadurch ab, dass der feine Längskiel des Halsschildes völlig fehlt oder nur sehr schwach angedeutet ist.

527. Ommata (Chrysaëthe) aureicollis n. sp. Obscure caerulea vel ex parte virescens, pronoto pallide aureoflavo; antennarum articulis 6-11 opacis nigris; pilis brevibus erectis vel setis pallidis vestita; dense punctata; genis elongatis, fronte sat lata; antennis dimidium elytrorum longe superantibus, apicem fere attingentibus, articulis $1-5$ infra setosis, 8-11 brevioribus et modice incrassatis, scapo punctato; prothorace latitudine longiore, subcylindrico, utrinque levissime rotundato, margine apicali et basali incrassato nigro; scutello subquadrato, apice truncato; elytris subintegris, dense profunde punctatis, medio utrinque leviter emarginatoangustatis, apice late oblique subemarginato-truncatis angulo exteriore magis producto, apicem abdominis fere attingentibus; pedibus subnitidis setosis, femoribus modice incrassatis, posticis elongatis apicem elytrorum attingentibus; prosterno subnitido foveato-punctato; mesosterno, metasterno abdominineque pubescentibus opacis, dense punctulatis, hoc in medio subnitido et fortius punctato. Long. corporis $10 \mathrm{~mm}$.

ab. discinotata n. ab. - Pronotum plaga magna nigra cum margine basali connexa ornatum.

Brasilien. - Reichsmuseum in Stockholm. 
Die Vorderbrust ist wie die ganze Unterseite bläulichgrün gefärbt.

528. Mecosaspis pyritosa n. sp. - Nitidissima, purpureoignita prothorace interdum ad latera virescente-micante; antennis pedibusque totis nigris, opacis; tarsis posticis niveohirtis; labro transverso nigro apice emarginato utrinque seta valida longa instructo; clypeo punctato; fronte minute punctulata profunde sulcata; mandibulis apice nigris; genis mediocribus; scapo antennarum simplici punctato, articulo tertio apice, reliquis per totam longitudinem extus profunde bisulcatis; vertice utrinque nigro-velutino; prothoracis disco modice elevato, utrinque foveato foveis parum profundis leviter nigro-pubescentibus, inter foveas et margines leviter striolato; scutello elongato, transverse sulcato, apice acutissimo; elytris remote punctatis, nudis, tantum ad basin utrinque leviter biimpressis et in depressionibus paullulum nigro-velutinis; prosterno utrinque ante coxas vitta hirsuta instructo, postice truncato et tuberculato; femoribus anterioribus infra prope apicem dentatis, posticis obsolete angulatis, apicem elytrorum haud vel vix attingentibus. Long. corporis 26$31 \mathrm{~mm}$.

๙ิ. Antennae apicem elytrorum fere attingentes. Segmentum ventrale qvintum apice emarginatum, segmento sexto parum longius, hujus lamina ventralis apice emarginata et dense ciliata.

․ Antennae tertiam partem apicalem elytrorum vix attingentes. Segmentum ventrale quintum elongatum apice obtuse rotundatum.

Kamerun: Joko. - Reichsmuseum in Stockholm.

Eine der schönsten mir bekannten Mecosaspis-Arten; durch die nackte Unterseite und die fast nackten Flügeldecken von $M$. Poggei verschieden. Die Epipleuren der Flügeldecken sind nicht erweitert.

529. Orthoschema tibiale n. sp. - Ferrugineum, flavopubescens; antennis scapo rufo excepto nigris; tibiis nigris, tarsis fuscis; ventre nitido nigro; elytris viridi-coeruleis vel violascentibus, apice rotundatis inermibus. Long. corporis $18-19 \mathrm{~mm}$. 
Brasilien (nach einem alten Stück aus Mniszech's Sammlung). - Reichsmuseum in Stockholm. Ein zweites Stück findet sich in F. Sahlberg's Sammlung. Die Art stimmt in Grösse und Körperform mit $O$. prasinipenne LuCAS überein und ist vielleicht nur eine Form von dieser Art.

530. Cyllene abnormis n. sp. - Antennae coxas posticas attingentes; scapus obconicus articulo 3:o multo longior. Prothorax transversus, utrinque valde aequaliter rotundatus, haud postice angulatus, in medio elytris haud angustior. Elytra prope suturam longitudinaliter obtuse unicostata, apice subacute rotundata, inermia: costae basin et apicem versus evanescentes. Prosternum postice elevato-truncatum et apice emarginatum. Metasternum antice subtruncato-declive, postice inter coxas triangulare. Femora haud carinata, apice inermia; postica segmentum ventrale tertium vix superantia; tarsi postici subbreves; articulus primus reliquis simul sumtis vix longior. - Subparallela, pilis adpressis rudis sordide flavescentibus fere undique vestita, infra cum pedibus pilis erectis pallidis praedita, brunnea; capite, prothorace, sternis, apice antennarum et femorum nigro-fuscis; capite piloso; pronoto subplano, unicolore, basin versus sensim angustato; scutello obtuse rotundato; elytris maculis vel fasciis obliquis irregularibus 5, prope suturam plus minus connexis, nigricantibus, vage determinatis ornatis. Long. corporis $14 \mathrm{~mm}$.

Bolivia. - Reichsmuseum in Stockholm.

Durch die völlig abgerundeten Seiten des Halsschildes, die unbewaffneten Flügeldecken und die Zeichnung von den typischen Arten ganz abweichend.

531. Neoclytus vitticollis n. sp. - Fig. 73. - Nigrofuscus; antennis, pedibus elytrisque brunneis vel flavescentebrunneis; signaturis flavo-tomentosis ornatus; capite (vertice genisque exceptis) flavo-tomentoso, fronte carina media nigra instructa; antennis brevibus, metasterni medium vix superantibus, flavido-brunneis, in medio infuscatis, ab articulo $5^{\circ}$ incrassatis, scapo elongato, tenui, quam articulo $3^{\circ}$ multo longiore, hoc quam $4^{\circ}$ paulo longiore, quam $5^{\circ}$ breviore, articulis 3-10 infra pilosis; prothorace subgloboso, basin versus angustato, carina media dorsali lata asperata instructo, infra dense flavotomentoso, supra fascia subapicali et basali in 
medio interruptis et utrinque vittis duabus obliquis antice abbreviatis flavotomentosis ornato, carina in medio fasciola parva transversa flava ornata; scutello flavido ad basin brunneo; elytris brunneis apicem versus pallidioribus grisescentibus, vitta obliqua humerali flavida fasciisque tribus transversis flavis ornatis, vitta prima obliqua prope suturam angulata et antrorsum prolongata nec suturam nec scutellum attingente, vitta secunda paullo latiore modice obliqua ad su-

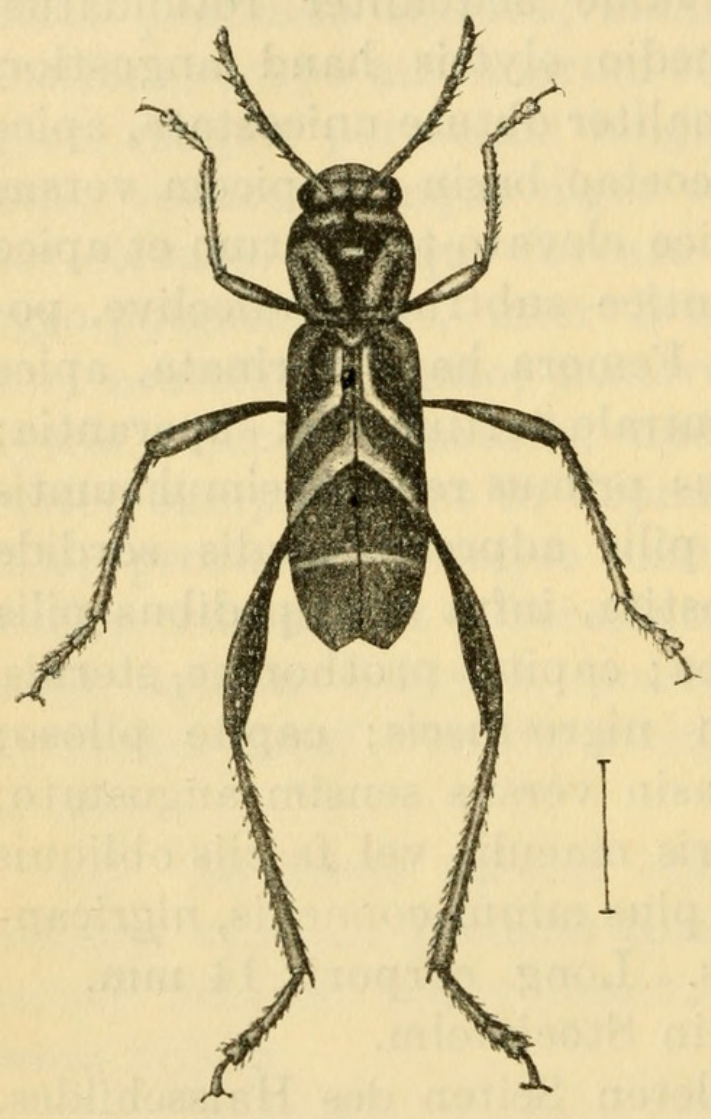
turam antrorsum triangulariter producta, tertia recta omnino transversa; pectore abdomineque fere omnino flavo-tomentosis maculis lateralibus mesoet metasterni cingulisque angustis basalibus segmentorum abdominis nigricantibus; femoribus posticis incrassatis dimidio fere abdomen superantibus apice bidentatis. Long. corporis $12 \mathrm{~mm}$. Peru: Pebas. Reichsmuseum in Stockholm.

Durch die Zeichnung des Halsschildes weicht diese Form von allen mir bekannten Arten ab. Die Zeichnung der Flügeldecken ist nach demselben Typus wie bei delicatus Goun.

Fig. 73. Neoclytus vitticollis AUrIv. angelegt.

532. Neoclytus niger n. sp. - Fig. 74. - Niger, infra cum pedibus et capite sat dense flavescente griseo-pubescens, in elytris signaturis griseo-tomentosis ornatus; vertice utrinque profunde punctato: prothorace latiusculo, ovali, in medio asperato, supra nigro utrinque ad basin sat late griseo; scutello griseo; elytris apice recte truncatis, totis nigris fascia transversa basali humeros tegente, fasciis duabus obliquis ad suturam mox pone scutellum et ad marginem lateralem conjunctis, maculaque magna suturali communi ante apicem, subtrigona dense griseo-tomentosis; segmentis duobus ultimis abdominis nigricantibus; articulo $1^{0}$ tarsorum posticorum valido reliquis simul sumtis parum longiore. Long. corporis 
$13 \mathrm{~mm}$. Brasilien. Provinz Bahia: Cachimbo. - Reichsmuseum in Stockholm.

Durch Körperform und Zeichnung nahe mit $N$. magicus Perty verwandt, ausser durch die Farbe aber auch durch die breiteren, an der Mitte des Seitenrandes vereinigten, schiefen Querbinden der Flügeldecken, die quer abgestuzten Flügeldecken und das etwas kürzere erste Glied der Hintertarsen verschieden.

533. Mecometopus bicinctus $\mathrm{n}$. sp. - Parvus, totus nigro-fuscus, prothorace tenue cinereo-pubescente, elytrorum plaga magna communi basali pone scutellum profunde bifida fasciaque lata pone medium sulphureis; plaga magna laterali metasterni segmentisque duabus primis abdominis etiam sulphureo-tomentosis; fronte plana elongata sublaevi; genis quam

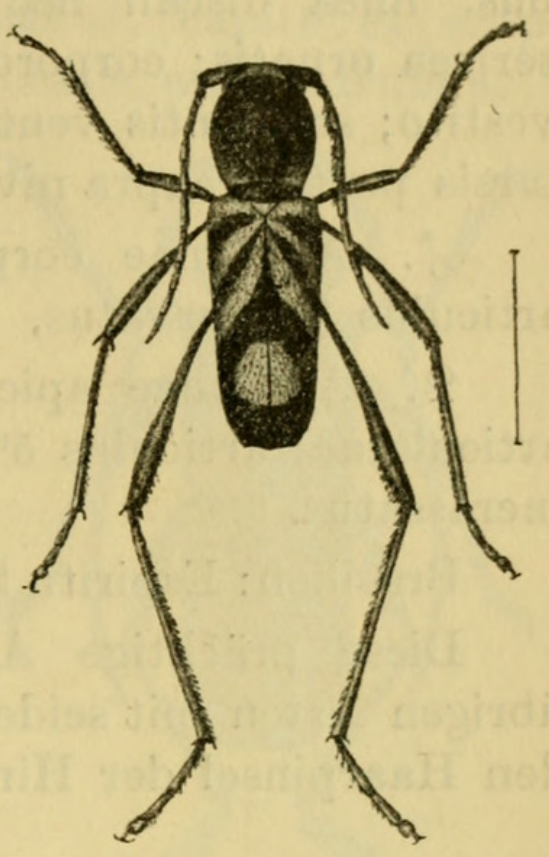

Fig. 74. Neoclytus niger AURIV. oculis vix brevioribus; prothorace elongato-ovali carina dorsali parum elevata aspera; scutello nigro; elytris apice subtruncatis angulo externo leviter producto; femoribus posticis apicem elytrorum longe superantibus. Long. corporis $9 \mathrm{~mm}$.

Brasilien: Espiritu Santo. - Reichsmuseum in Stockholm.

Durch die schwarze Grundfarbe und das Fehlen des gelben Mittelfleckes der Flügeldecken von allen verwandten Arten verschieden.

534. Cosmisoma tibiale n. sp. - Piceum vel nigrofuscum, interdum ferrugineum, elytris, tibiis tarsisque semper, antennis saepe obscurioribus, nigricantibus; antennarum articulo $5^{\circ}$ apice, tibiis posticis paullo infra medium scopa magna nigra aut ferruginea ornatis; fronte brevi subquadrata, leviter striolata et obsolete punctata; vertice striolato; antennarum scapo subpyriformi antice ad basin sulcato; prothorace latitudine basali multo longiore apicem versus leviter angustato lateribus in medio fere rectis, pone apicem et ante basin profunde constricto, sulco subbasali supra in medio antror- 
sum valde angulato; pronoto supra paullo inaequali subnitido, minute punctulato et tenuiter nigro-velutino; scutello lato albido-sericeo; elytris basi recte truncatis, supra planis, apice acuminatis, obsolete violascente vel chalybeo micantibus, linea discali nec basin nec apicem attingente aureosericea ornatis; corpore infra praesertim ad latera pube nivea vestito; segmentis ventralibus utrinque macula nivea ornatis; tarsis posticis supra niveo-sericeis. Long. corporis $17-20 \mathrm{~mm}$.

$\delta$. Antennae corpore duplo longiores, 12-articulatae; articulus $5^{\text {us }}$ curvatus, $12^{\text {us }}$ elongato-conicus.

․ Antennae apicem elytrorum parum superantes, 11articulatae; articulus $5^{\text {us }}$ rectus, ultimus brevis prope apicem incrassatus.

Brasilien: Espiritu Santo. - Reichsmuseum in Stockholm.

Diese prächtige Art unterscheidet sich sofort von den übrigen Arten mit seidener Längslinie der Flügeldecken durch den Haarpinsel der Hinterschienen.

535. Cosmisoma tenellum n. sp. - Rufo-ferrugineum; vertice, margine apicali et basali pronoti, scutello, elytris, clava femorum, tibiis tarsisque virescente-fuscis vel chalybeonigris; antennis plus minusve infuscatis; fronte lata transversa, dense rugoso-punctulata, inter antennas tenue sulcata; genis brevibus quam lobis oculorum inferioribus plus duplo brevioribus; antennarum scapo elongato obconico rude punctato, antice ad basin leviter sulcato et carinulato, articulis 1-4 infra laxe pilosis, $5^{\circ}$ ante medium haud piloso apice scopa nigra instructo; prothorace elongato latitudine basali duplo longiore, subcylindrico parte media fere aequali haud nodulosa, utrinque leviter arcuato, sulcis apicali et basali parum profundis, parte media (inter sulcis) rubra dense punctata vitta fere laevi nitida; scutello apice obtuse rotundato; elytris dense coriaceo-punctulatis tenuiter pubescentibus, apice obtuse acuminatis. Long. corporis $9-11 \mathrm{~mm}$.

Brasilien: Minas Geraes; Rio Janeiro. - F. SAHLberg. Reichsmuseum in Stockholm und SAHLberg's Sammlung.

Die Art steht in SaHLBerg's Sammlung als tenellum Mannerh., ist aber von C. Brullei Muls., welche nach GouNELLE mit tenellum identisch sein sollte, gut verschieden. 
536. Callancyla tuberculicollis n. sp. - Fig. 75 Breviter pilosa, rubra; elytris nigro-coeruleis; abdomine, metasterno (ex parte), scutello, tibiis tarsisque nigris; femoribus posticis in medio, articulis 3-9 antennarum ad basin et ultimis fere totis interdum nigricantibus; capite et scapo antennarum opacis, dense rugoso-punctatis, antennarum articulis 2-11 nitidis $3-9$ supra ad basin sulcatis; prothorace nitido, tranverso, utrinque in medio valde rotundato, supra fortiter quadrigibboso, leviter punctulato margine apicali et basali anguste nigro; elytris densissime profunde punctatis; femoribus intermediis apice unispinosis, posticis bispinosis spina interna multo longiore. Long. corporis $10-12 \mathrm{~mm}$.

Bolivien: Mapiri. - Reichsmuseum in Stockholm.

Durch die Form und Bildung Fig. 75. Callancyla tuberculides Halsschildes sofort von den

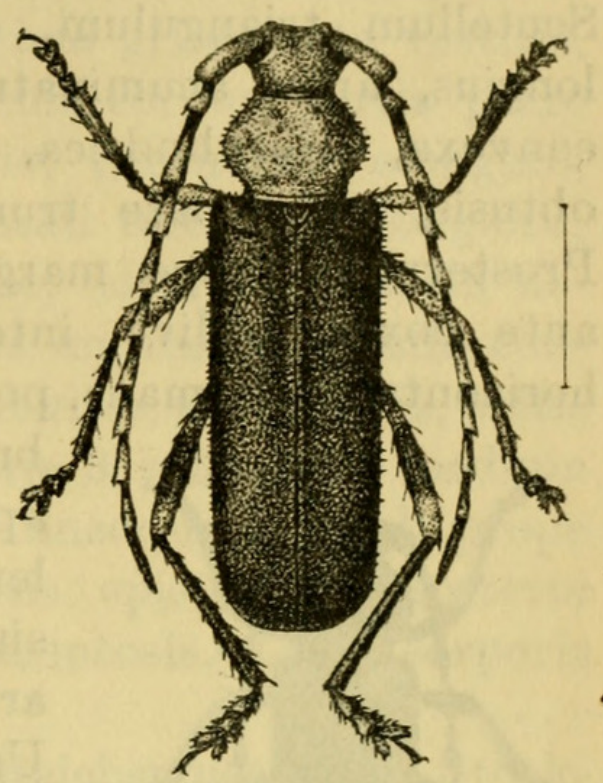
collis AuRIv. übrigen bisher beschriebenen Arten verschieden. Auf der Scheibe des Halsschildes stehen vier grosse stumpfe Höckerchen und ausserdem an jeder Seite ein kleineres.

Andraegoidus nov. gen.

Mandibulae breves crassae. - Labrum breve dense setosum. - Epistoma distinctum. - Frons brevis, subverticalis, antice profunde transversim impressa, medio sulcata. Genae mediocres, lobis inferioribus oculorum breviores, a fronte tuberculis antenniferis separatae ibique foveatim impressae. - Oculi profunde emarginati, supra aeque late ac condyli antennarum distantes; lobi inferiores trigoni. - Tuberculi antenniferi magni, profunde emarginati, apice obtuse cornuti; antennae maris corpore quarta fere parte longiores inermes; scapus obconicus, pronoti marginem anticum vix superans; articulus tertius scapo parum, articulo $4^{\circ}$ sat longior; articuli $5-10$ subaequales $4^{\circ}$ paullo longiores; $11^{\text {us }}$ elongatus, $3^{\circ}$ longior, apice acuminatus et leviter curvatus. - 
Prothorax maris transversus, magnus, tumidus, utrinque ante medium tumidus et pone medium tuberculo parvo obtuso armatus, fere undique punctura densa rugulosa obsitus fascia media transversa irregulari elevata, inaequali subnitida ornatus; margo apicalis recte truncatus, posticus in medio latissime et obtusissime lobatus et utrinque levissime sinuatus. Scutellum triangulum, elongatum, latitudine basali duplo longius, apice acuminatum, utrinque marginatum. - Elytra convexa, subcylindrica, ad basin oblique truncata humeris obtusis, apice late truncata angulo exteriore dentato. Prosternum prope marginem anticum tuberculo armatum, ante coxas declive, inter coxas carinam obtusam omnino horizontalem formans, pone coxas truncatum. - Mesosternum

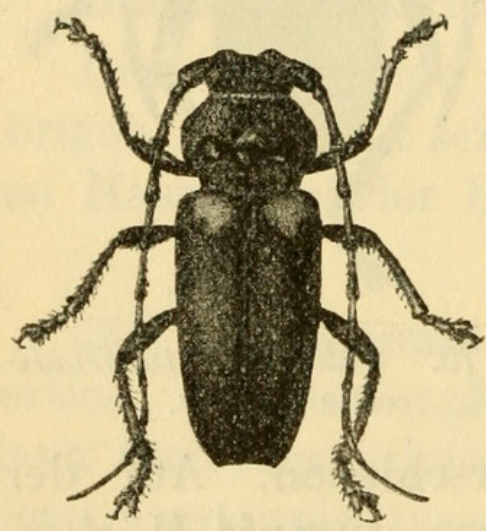

Fig. 76. Andraegoidus humeralis AURIV. breve, truncatum, postice emarginatum, apicem metasterni excipiens. - Femora leviter incrassata, apice inermia; tibiae simplices haud carinatae; tarsi breves, articulus primus $2^{\circ}$ parum longior. Unguiculi subdivaricati.

Diese neue Gattung ist offenbar mit Aegoidus BuQu. nahe verwandt und weicht hauptsächlich durch die unbewaffneten Schenkel und die verschieden gebildete Vorder- und Mittelbrust, sowie durch die, wenigstens beim $\delta$, ganz abweichende Bildung des Halsschildes ab.

537. Andraegoidus humeralis n. sp. - Fig. 76. Niger, supra nudus, subnitidus, infra breviter setulosus; gula, fovea frontis, macula parva inter oculos, macula triangula in medio pronoti, plaga ad basin elytrorum, margine antico prosterni cum tuberculo, processu prosterni, medioque mesoet meta-sterni rubris; antennarum articulis $1^{\circ}$ et $3^{\circ}-10^{\circ}$ ad basin plus minus late rufescente annulatis; capite rude punctato, vertice in medio nitido sparsim punctato; prothorace ad maximam partem punctura densissima sexuali obsito, opaco, fascia transversa irregulari dorsali nitida parum punctata in medio prædito; scutello laevi in medio excavato; elytris leviter punctulatis; corpore infra cum pedibus fortius punctato, abdomine punctulato subnitido. Long. corporis $30 \mathrm{~mm}$.

Argentinien. - Reichsmuseum in Stockholm. - Nur 10. 


\section{Lamiidae.}

538. Mesolita simplicicollis n. sp. - Parva, angusta, nigrofusca, antennis pedibusque rufo-brunneis, elytris ad basin obscuris, deinde pallidioribus fusco-brunneis; capite et prothorace immaculatis, pube tenuissima grisescente vestitis, dense minutissime punctulatis; antennis corpore tertia parte longioribus, haud distincte annulatis; prothorace elongato, basin versus angustato, latitudine basali fere duplo longiore; scutello albido-vel flavido-pubescente; elytris ad basin depressis subplanis et punctis perpaucis impressis, deinde convexis et paullulum dilatatis, apice breviter unispinosis, vittis duabus obsoletis ante medium, punctis 3 vel 4 pone medium in serie obliqua transversa positis, lineaque suturali prope apicem albido-vel grisescente tomentosis; episternis mesosterni et epimeris metasterni dense flavotomentosis. Long. corporis $7-8 \mathrm{~mm}$.

Australien: Neu Süd Wales. - Reichsmuseum in Stockholm.

Celosterna (Blanch) Thoms.

Obwohl Lacordaire in der Beschreibung der Gattung Celosterna schreibt: »Mesosternum subvertical et obtusement tuberculé en avant, horizontal en arrière» führt er doch in seiner Gattungsübersicht (p. 302) Celosterna irrtümlich zu der Abteilung, welche durch "Mesosternum inerme en avant» ausgezeichnet sein soll. Dadurch ist es erklärlich, dass einige Arten mit sanft gebogener und unbewaffneter Mittelbrust auch zu Celosterna geführt worden sind.

Bei der typischen Art, C. scabrator F., und allen echten Celosterna-Arten ist indessen die Mittelbrust vorne senkrecht abfallend und mit einem Höcker bewaffnet. Sie sind ferner durch die grossen Augen, die schmale Stirn, welche höher als breit ist, und durch die an der Spitze seicht ausgerandeten und zweispitzigen oder wenigstens am Nahtwinkel mit einem Dorn bewaffneten Flügeldecken ausgezeichnet.

Für die übrigen Arten, welche eine verschieden gebildete Mittelbrust haben, ist die folgende neue Gattung zu errichten. 
Cremnosterna n. gen.

A genere Celosterna, cui affinis, differt mesosterno declivi, leviter sulcato, inermi, fronte lata subquadrata elytrisque apice inermibus conjunctim rotundatis vel leviter truncatis.

Typus: "Monohammus» carissimus Pasc.

$\mathrm{Zu}$ Cremnosterna gehören ferner plagiata WHITE und wahrscheinlich die mir unbekannten elegans WATERH. und Fleutiauxi LAME ERE.

539. Celosterna scabrator F. var. griseator n. var. A forma typica corpore tomento unicolore cinerascente-griseo scutelloque albido differt,

Südostindien: Madras und Shembaganur. - Reichsmuseum.

Die Behaarung ist bei der Hauptform gelb, bei der Varietät spinator grau mit zahlreichen gelblichen oft netzförmig vereinigten Flecken und bei der neuen Form einfarbig grau. Bei genauer Untersuchung sind jedoch Spuren einer Fleckenzeichnung zu entdecken.

540. Macrochenus isabellinus n. sp. - Niger; genis, elytris, lateribusque abdominis brunneo-rufulis, pube grisescente-albida vestitis; lateribus frontis, genis latissime vittisque tribus verticis albido-pubescentibus; prothorace vittis 5 subaeque latis albidis; scutello albido; elytris quasi isabellinis bumeris maculisque magnis subquadratis aut subrotundatis, late separatis vel ex parte conjunctis, distinctissimis nigris; abdomine utrinque maculis 5 nigris, prima maxima, ornato, in medio cinereo-pubescente, segmentis postice albidociliatis. Long. corporis $28 \mathrm{~mm}$.

Tonkin: Mauson Berge, 2-3,000'. Frubstorfer. - Reichsmuseum in Stockholm.

Von dem nahe verwandten $M$. Guerini White durch die Farbe und die grösseren, weiter getrennten schwarzen Flecke der Flügeldecken sowie durch die schmälere Mittelbinde des Halsschildes verschieden.

541. Macrochenus tonkinensis n. sp. - Niger, pube tenui cinerascente vestitus; macula utrinque frontis, vitta genali, vittis tribus verticis lateralibus abbreviatis et an- 
gustis, vittis utrinque binis prothoracis, guttisque inaequalibus sparsis elytrorum, pectoris abdominisque flavescente-albido-pubescentibus; pronoto transversim ruguloso modice prolongato; scutello obtuse rotundato fere nigro; elytris ad humeros granulis paucis praeditis, a basi ultra medium subseriatim punctatis punctis apicem versus sensim minoribus, apice singulatim emarginatis et bidentatis. Long. corporis $24-25 \mathrm{~mm}$.

Central Tonkin (Fruhstorfer); Yunnan.

Beim $\delta$ sind die Fühler mehr als doppelt so lang wie der Körper und fast schwarz, beim $q$ erreichen sie nicht die doppelte Körperlänge und sind an der Wurzel der Glieder 4-11 schmal grau geringelt. $M$. tonkinensis weicht durch das Fehlen der Mittellängsbinde des Halsschildes und die hellen Tropfflecken der Flügeldecken von allen übrigen Arten ab. Von diesen Flecken sind sieben etwas grösser als die anderen; von denselben steht einer an der Wurzel zwischen der Schulter und dem Schildchen, drei hinter diesem längs der Mitte, einer nahe vor der Spitze und zwei am Seitenrande vor der Mitte. Die Vorderbrust hat drei Längsbinden, von denen die mittlere nach vorn abgekürzt ist; an den Seiten der Mittel- und Hinterbrust finden sich grössere, mehr oder weniger vereinigte Flecke und an jedem Segmente des Hinterleibes ein gerundeter heller Fleck am Seitenrande und ausserdem zwei grössere Flecke nahe, an der Mitte des ersten Ventra]gliedes.

542. Pharsalia suturalis n. sp. - Elongata, nigra, infra griseo- et ferrugineo-tomentosa, supra in capite et pronoto ferrugineo-vittata, in elytris sat dense ferrugineo-maculata; capite fascia pone oculos vittisque duabus verticis ferrugineis; tuberculis antenniferis apice leviter divergentibus, inermibus; antennis maris corpore plus duplo longioribus, brunneis articulis $4-11$ ad basin obsolete grisescentibus, articulo $3^{\circ}$ quam scapo fere duplo longiore; pronoto utrinque spina conica mediocri armato, supra parum inaequali et granulis nonnullis consperso, vittis 5 irregularibus ferrugineis ornato; scutello obtuso toto ferrugineo; elytris apicem versus sensim angustatis, ad basin in medio tuberculo parvo obtuso instructis, apice truncatis et bidentatis dente suturali longiore 
spiniformi, ad basin subseriatim profunde punctatis, punctis apicem versus sensim minoribus. Long. corporis $16 \mathrm{~mm}$.

Assam. - Reichsmuseum in Stockholm.

Kommt der $P h$. variegata recht nahe, weicht aber durch die kleinere höckerförmige Erhöhung an der Wurzel der Flügeldecken und die verschiedene Bewaffnung der Flügeldeckenspitzen ab.

543. Pharsalia ferruginea var. niasica n. var. - Weicht von der Beschreibung und Abbildung der Hauptform dadurch $a b$, dass die Behaarung der Unterseite und die Flecke der Oberseite hellgelb, fast strohgelb und nicht rostrot sind. Die Querbinde der Flügeldecken ist breiter und die dahinter gelegenen samtschwarzen Flecke grösser als bei ferruginea. Die kleinen weissen Borsten, welche bei ferruginea die Beine bekleiden, kann ich bei niasica nicht entdecken; sonst stimmt Gahans Beschreibung sehr gut auch auf niasica. Das dritte Fühlerglied ist kaum länger als das erste. Die Scheibe des Halsschildes hat sieben kleine Höckerchen, zwei in einer vorderen und fünf in der hinteren Querreihe. Die unteren Augenlappen sind klein und viel, fast doppelt, kürzer als die Wangen. Körperlänge $20-23 \mathrm{~mm}$. holm.

Insel Nias. - Ein Pärchen. - Reichsmuseum in Stock-

Die Fühlerhöckerchen sind völlig zusammenstehend und an der Spitze in einen Dorn auslaufend.

544. Pharsalia variegata n. sp. - Nigra, infra griseopubescens, supra vittis et maculis ferrugineis ornata; capite vittato; tuberculis antenniferis subcontiguis, apice anguste divergentibus; antennis fuscis articulis 4-11 ad basin obsolete griseis, articulo $3^{\circ}$ quam scapo multo longiore; maris corpore plus duplo longioribus; pronoto leviter transverso, parum inaequali, in medio fere plano, ferrugineo-bivittato maculisque minutis ferrugineis consperso, utrinque in medio spina mediocri armato; scutello ferrugineo-tomentoso; elytris sat angustis, ad basin truncatis, humeris subrectis et carina brevi basali modice elevata instructis, apice truncatis et bidentatis dente suturali obsoleto, dente exteriore longiore, subnitidis, maculis ferrugineis conspersis et utrinque maculis binis parvis sublateralibus flavidis vel albidis ornatis, ad basin sat 
profunde punctatis, sed non granulatis, punctis apicem versus multo minoribus; abdomine subnudo nitido segmentis apice ferrugineo-ciliatis. Long. corporis $13-15 \mathrm{~mm}$.

Ostindien: Madura und Sïkkim. - Ein Pärchen. Reichsmuseum in Stockholm.

Beim $q$ sind die Fühler nur wenig länger als der Körper.

545. Pharsalia setulosa n. sp. - Nigra tomento brunneo vestita; corpore infra cum pedibus, capite et scapo antennarum setis minutis albidis dense conspersis; antennis brunnescentibus articulis $4-11$ ad basin late grisescentibus; prothorace modice transverso utrinque in medio spina magna valida armato, supra parum inaequali, utrinque minute nigro-granulato, postice in medio tuberculo singulo obsoleto nigro instructo; scutello latissime rotundato; elytris subtrigonis ad basin truncatis humeris acute productis crista basali alte elevata et tuberculata, apice truncatis et extus dentatis, ad basin granulatis et punctatis, punctis apicem versus sensim minoribus, brunneis, maculis fuscis variegatis, ante medium fascia obliqua brunneo-maculata, albida et ante apicem maculis paucis elongatis albidis ornatis; corpore infra immaculato. Long. corporis $18 \mathrm{~mm}$.

Insel Palawan. - Reichsmuseum in Stockholm.

Ist möglicherweise mit der mir unbekannten $P h$. supposita Pasc. verwandt, hat aber keine schwarzen Seitenflecke des Hinterleibes und eine verschiedene Zeichnung der Flügeldecken.

546. Apriona borneensis n. sp. - Elongata, subcylindrica, impunctata, fusca, tomento denso supra pallide incano-cinereo, infra obscuriore virescente-flavido vestita; infra vitta lata laterali nivea ornata; antennis unicoloribus fuscis, haud annulatis; pronoto parum inæquali sulcis transversis distinctis, in medio utrinque sulco obliqvo abbreviato impresso et pone sulcum punctis nonnullis piliferis instructo; scutello apice subangulatim rotundato; elytris subparallelis apice leviter truncatis angulo suturali spinoso; angulo exteriore angulato vel obsolete dentato, ad basin irregulariter granulatis, granulis ad latera pone humeros magnis transversis, inter humeros et scutellum parvis et perpaucis longe distantibus. Isong. corporis $38-49 \mathrm{~mm}$.

$\delta$. Antennae corpore sesqui longiores articulo $7^{\circ}$ apicem elytrorum longe superantes; articulus ultimus paen- 
ultimo fere duplo longior. Segmentum ventrale ultimum apice late truncatum et leviter emarginatum. ․ Antennae corpore tertia parte longiores, articulo $7^{\circ}$ apicem elytrorum vix attingente; articulus ultimus paenultimo parum longior. Pygidium supra canaliculatum, apice profunde fissum; segmentum ventrale ultimum apjce incisura profunda instructum.

Borneo: Kina Balu. - Reichsmuseum in Stockholm.

547. Choeromorpha pigra n. sp. - Nigro-fusca, pube grisea vel flavescente grisea e maxima parte inaequaliter vestita; fronte nitida rugoso-punctata, longitudinaliter late sulcata et in medio carinata; vertice et temporibus vittis 7 griseis ornatis: prothorace aequaliter convexo, antice utrinque tuberculo distincto armato, undique dense punctulato et basin versus punctis paucis impresso, vittis albidis $4-7$ parum distinctis ornato et inter vittas griseo-pubescente; scutello plano, griseo; elytris fuscis et fusco-pubescentibus, maculis griseis elongatis majoribus apicem versus magis congestis ornatis et inter maculas punctis griseis dense conspersis; corpore infra ad latera dense flavido-tomentoso, in medio nitido subnudo segmentis ventralibus apice flavo-ciliatis; antennis fusco-brunneis articulis $3-6$ ad basin late albidis, scapo medium pronoti fere attingente, articulo $3^{\circ}$ brevi quam $4^{\circ}$ multo breviore, $4^{\circ}$ elongato scapo fere aequali: tibiis intermediis et posticis extus apicem versus dense hirsutis. Long. corp. $12-20 \mathrm{~mm}$.

๙. Pedes antici validi elongati. Antennae corpore longiores, articulo $7^{\circ}$ apicem elytrorum attingentes. Segmentum ventrale ultimum transversum simplex.

q. Pedes antici haud elongati. Antennae corpore breviores. Segmentum ventrale ultimum, subtriangulum, longitudinaliter sulcatum.

Java. - Reichsmuseum in Stockholm.

Diese auf Java nicht seltene Art ist vermutlich dieselbe, welche DeJEan als pigra bezeichnete, die aber nie beschrieben worden ist. Die Arten der Gattung Choeromorpha sind nicht nur durch die Bildung des Mesosternums, sondern auch dadurch ausgezeichnet, dass das Halsschild, das Schildchen und der Wurzelteil der Flügeldecken völlig in derselben Ebene liegen. Dadurch weichen sie sofort von allen Mesosinen, 
welche ein gegen die Wurzel deutlich abfallendes Schildchen haben, ab.

548. Choeromorpha albomaculata n. sp. - Atra et atro-tomentosa, lineis maculisque albis ornata; fronte et vertice lineis tribus, genis temporibusque vitta ornatis; prothorace antice leviter depresso utrinque inermi, supra vittis tribus ad medium desinentibus, ad latera et ad basin maculis nonnullis ornato; scutello atro immaculato; elytris elongatoovalibus humeris productis, apicem versus sensim angustatis, apice conjunctim late rotundatis, impunctatis, singulis fascia transversa ante medium ad suturam late interrupta maculisque 12 (4 geminatis suturalibus, 4 discalibus et 4 lateralibus, quarum ultima apicali) albis ornatis; corpore infra pedibusque atris immaculatis, segmentis ventralibus apice breviter cinereo ciliatis; antennis nigris articulo $4^{\circ}$ ad basin anguste albido-tomentoso, feminae corpore paullulo longioribus. Long. corporis $20 \mathrm{~mm}$.

Insel Talauer. - Reichsmuseum in Stockholm.

Ein Weibchen. Die Mittelbrust ist am Vorderrande sehr breit, fast so breit wie der Zwischenraum zwischen den Vorderschenkeln.

549. Monotylus flavescens n. sp. - A M. Klingi Kolbe, cui simillimus, corpore toto tomento flavescente vestito tantum differre videtur.

Kamerun: Joko. - Reichsmuseum in Stockholm.

Ich habe nur Weibchen gesehen. Vielleicht nur eine Farbenveränderung von $M$. Klingi, welche mir auch aus derselben Gegend von Kamerun vorliegt.

550. Rhodopis quadrituberculata n. sp. - Fusca, griseo-pubescens et fllavosignata, elytris àlbido-pubescentibus plagis utrinque tribus maculisque fuscis variegatis; fronte punctulata infra et ad latera flavescente, vertice flavo-bivittato; temporibus vitta obliqua flavida; antennis corpore multo longioribus articulis ad basin late albidis; prothorace subquadrato utrinque in medio acute spinoso et supra tuberculis duobus alte elevatis armato, discrete punctato et vittis 5 flavis (tribus dorsalibus) ornato; scutello obtuso flavotomentoso; elytris ad basin granulatis et prope scutellum Arkiv för zoologi. Bd 13. N:o 9. 
tuberculatis humeris prominulis, apicem versus sensim angustatis, apice obtuse truncatis; pedibus albido-tomentosis, genubus, apice tibiarum tarsisque nigris, margine apicali segmentorum ventralium flavescente. Long. corporis 17-19 mm.

Südostindien: Madura. - Reichsmuseum in Stockholm.

Durch die zwei hohen Höckerchen auf der Rückenseite des Halsschildes von allen anderen Rhodopis-Arten verschieden.

551. Arrhenotus salomonum n. sp. - Fig. 77. - Carina lateralis pronoti continua, subrecta, leviter crenulata, prope apicem obliqua, vix autem angulata; tuberculus lateralis parvus parum distinctus; elytra apice truncata inermia; scu-

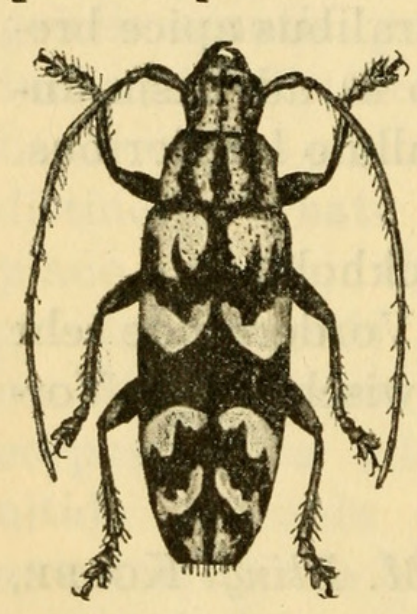
tellum transversum, antice fere truncatum. Niger, infra pube tenui cinerascente vestitus, supra subnudus, signaturis aureo-metallicis vel cupreo-micantibus ornatus; antennis fusco-brunneis, scapo nigricante articulo $3^{\circ}$ multo breviore; capite paucipunctato bivittato; pronoto quadrivittato utrinque rude punctato vitta media nitida laevi; scutello utrinque maculato; elytris haud sulcatis, irregulariter punctatis punctis apicem versus Fig. 77. Arrhenotus minoribus, vittis binis brevibus basalibus salomonum AURIV. interiore breviore fasciisque tribus obliquis prima ante medium, secunda paullo pone medium, tertia interrupta subapicali ornatis, apice ipso maculis parvis consperso. Long. corporis $16-17 \mathrm{~mm}$.

Salomonen: Insel Bougainville. - Reichsmuseum in Stockholm.

Erinnert durch die Zeichnung der Flügeldecken an Tmesisternus cupreosignatus AURIV.

552. Mulciber lineatus n. sp. - Atrofuscus, subnitidus, undique setis albidis sparsis instructus, supra subnudus lineis longitudinalibus flavis ornatus, infra ad latera late flavidopubescens, pedibus dense flavido-pubescentibus obsolete fuscoconspersis; antennis flavescente-griseo-tomentosis corpore vix longioribus; fronte lata inaequali; pronoto transverso, ad basin utrinque emarginato, nitido, linea utrinque longitudinali marginibusque basali et apicali flavis, punctis paucis sparso 
vitta lata media omnino laevi; scutello transverso in medio flavo-pubescente; elytris apicem versus leviter angustatis apice truncatis, angulo exteriore spinoso, ad basin subnudis et dense granulatis, deinde pube fusco-brunnea vestitis, singulis lineis 5-6 longitudinalibus plus minus connexis ornatis, prima et secunda ad scutellum incipientibus prima suturali, secunda excurvata, sed deinde in medio cum prima connexa, tertia brevissima basali, quarta inter tertiam et humerum exeunte, bis curvata et usque ad apicem continuata quinta et sexta ab humero exeuntibus, ante medium connexis et apicem haud attingentibus, linea obliqua cum linea quarta conjunctis; prosterno curvato; mesosterno antice subdeclivi et tuberculo parvo armato; antennis (feminae?) apicem elytrorum vix attingentibus, articulo $3^{\circ}$ elongato quam scapo duplo, quam $4^{\circ}$ triplo longiore. Long. corporis $21 \mathrm{~mm}$.

Neuguinea: Sattelberg. - Collectio Hauser.

Die Art ist sofort durch die gelbe Linienzeichnung der Oberseite von allen anderen beschriebenen Arten verschieden und erinnert in dieser Hinsicht etwas an Grammoxyla hieroglyphica ReDTenB.

553. Catapausa inermis n. sp. - Brunnea, supra pube flavescente grisea vestita, infra e magna parte nuda nitida, pedibus fusco-variegatis; elytris ad medium baseos macula parva flavida ornatis; fronte transversa flavida; genis lobis inferioribus oculorum vix brevioribus; capite et pronoto punctatis hoc vitta media laevi; scutello valde transverso et obtuso; elytris apice suboblique leviter truncatis inermibus angulo suturali obtuso paullulum producto, a basi ultra medium granulato-punctulatis et seriebus $2-3$ granulorum majorum valde distantibus ornatis; prosterno tuberculo magno obtuso armato; mesosterno antice truncato tuberculo parvo armato; scapo antennarum difformi extus pone medium obtuse tuberculato, articulis 5-10 basi apiceque annulo brevissimo pallido ornatis. Long. corporis $15 \mathrm{~mm}$.

Neu Guinea: Sattelberg. - Collectio Hauser.

Erinnert an Mulciber Linnei Tномs., ist aber kleiner und mehr eintönig gefärbt, ohne Zeichnungen auf den Flügeldecken, mit Ausnahme eines kurzen gelben Striches an der Mitte der Wurzel. Durch die an der Spitze unbewaffneten Flügeldecken weicht die Art von allen mir bekannten ver- 
wandten Formen ab. Die Augen sind sehr tief ausgerandet, nicht aber »subdivisé» wie bei Mulciber und darum führe ich die Art zu der Gattung Catapausa.

Sormidomorpha nov. genus.

(Crinotarsini).

Oculi subdivisi. - Frons lata transversa. - Genae breves. - Caput pone oculos leviter constrictum. - Prothorax transversus, apice truncatus, utrinque prope medium tuberculo armatum, ad basin sulco unico profundo instructum. Scutellum transversum, apice late truncatum. - Elytra sat convexa, apicem versus sensim angustata, apice singulatim rotundata. - Prosternum inter coxas fere planum, postice productum et truncatum, in emarginatura mesosterni exceptum. - Mesosternum antice latissimum, late et profunde emarginatum, truncatum. - Processus intercoxalis abdominis triangularis, acutus. - Femora mediocria, parum incrassata. - Tibiae intermediae obsolete sulcatae. - Tarsi breves, lati. - Unguiculi magni divaricati. - Antennae (feminae) corpore tertia parte longiores infra ciliatae; scapus tuberculum lateralem pronoti attingens apice incrassatus.

In der Bildung der Vorder- und Mittelbrust stimmt diese Gattung mit Heteroclytomorpha überein, weicht aber durch die ausgesperrten Klauen von den Homonaeinen ab und muss darum zu den Crinotarsinen gefübrt werden. Von den beiden bisher bekannten Gattungen dieser Gruppe weicht sie aber durch die Bildung der Mittelbrust ab.

554. Sormidomorpha unicolor n. sp. - Brunnea, tota pube grisescente vestita, immaculata, punctata; punctis capitis et pronoti pubescentia plus minus occultis; elytris dense punctatis punctis apicem versus minoribus; antennarum articulo tertio elongato humeros longe superante; processu prosterni leviter sulcato; segmento ultimo ventrali elongato, apice truncato et leviter bisinuato, medio sulco lato parum distincto instructo (femina?). Long. corporis $23 \mathrm{~mm}$.

Salomon Inseln: Bougainville. - Reichsmuseum in Stockholm und Collectio Hauser. 
Megalofrea nov. gen.

A genere Frea, cui proxime affinis, differt lobis inferioribus oculorum angustis, subelongatis, elytrisque fasciculis $2-3$ nigris ornatis.

Typus Eumimetes humeralis VollenH.

Die Arten dieser Gattung wurden früher zu Eumimetes geführt, weichen aber von $E$. sparsus recht erheblich ab. Eumimetes fällt dagegen mit Frea zusammen. Bei Frea sind die unteren Augenlappen kürzer und breiter, gewöhnlich deutlich transversell oder höchstens subquadratisch.

Die Megalofrea-Arten sind alle einander sehr ähnlich und nur aus Madagaskar bekannt.

555. Eunidia castanoptera n. sp. - Atra, punctulata, pube cinerascente vestita, temporibus et pronoto nitidis subnudis irregulariter punctatis; elytris castaneis, dense punctatis, pube subtilissima grisescente vestitis apice rotundatis; antennis feminae corpore parum longioribus nigris articulis 4-11 ad basin cinereo-annulatis, scapo dense punctulato, subnitido, articulo $3^{\circ}$ quam $2^{\circ}$ plus duplo longiore apice extus acute dentato; oculorum lobis inferioribus elongatis latitudine multo longioribus, genis brevissimis. Long. corporis $10 \mathrm{~mm}$.

Ostafrika: Mulango Kitwi. - Collectio Hauser.

556. Esthlogena foveolata n. sp. - Infra cum pedibus fronteque nigra tenuiter cinereo-pubescens; supra brunnea, vertice, pronoto elytrisque dense flavo-tomentosis punctis magnis foveiformibus valde sparsis instructis; tuberculis lateralibus margineque basali pronoti, antennis, scutello apiceque summo elytrorum nigris cinereo-pubescentibus; lobis oculorum transversis; pronoto supra ante medium binodoso et utrinque prope apicem tumidiusculo; elytris apice subangulato-acuminatis; femoribus anticis incrassatis interdum rufescentibus. Long. corporis $12-14 \mathrm{~mm}$.

Bolivia. - Reichsmuseum in Stockholm.

557. Bisaltes subreticulatus n. sp. - Brunneus, undique tomento pallide flavido vel testaceo vestitus, leviter brunneovariegatus; lineis duabus dorsalibus approximatis pronoti, 
vitta brevi suturali pone scutellum lineisque flexuosis tenuibus subreticulatim connexis pone medium elytrorum nigris vel brunneo-fuscis; antennis pallidis, stramineis, articulis $5^{\circ}$, $7^{\circ}, 9^{\circ}$, apice articuli $4^{\mathrm{i}}$ et margine apicali articulorum $6^{\mathrm{i}}, 8^{\mathrm{i}}$, $10^{\mathrm{i}}$ et $11^{\mathrm{i}}$ atris; lobis inferioribus oculorum parvis elongatis; mesosterno lato, truncato, tumidiusculo; elytris punctis perpaucis sparsis impressis. Long. corporis $12 \mathrm{~mm}$.

Süd Brasilien: Sao Leopoldo. - Reichsmuseum in Stockholm.

558. Ischiocentra (?) alternans n. sp. - Nigrofusca, vittis maculisque ochraceo-flavis variegata; antennis, scapo nigro excepto, brunneis, articulis $4,6,8$ (et 10) ad basin laete flavo annulatis; fronte angusta, latitudine multo altiore, obsolete punctulata, utrinque flavo-lineata; genis lobis oculorum parum brevioribus; tuberculis antenniferis erectis subcontiguis fissura angusta profunda separatis, apice intus processu auriculato erecto armatis; temporibus vitta obliqua, vertice vitta unica flavida ornatis; prothorace leviter transverso, subquadrato, utrinque pone medium tuberculo obtuso nigro armato, supra fere aequali vittisque tribus flavidis ornato; scutello obscuro vel leviter flavido-pubescente; elytris bumeris prominulis nigris, disco inter humeros et scutellum longitudinaliter obtuse leviter elevato, apicem versus sensim angustatis apice rotundatis, ad basin fortius, apicem versus obsoletius irregulariter punctatis, undique maculis irregularibus plus minus confluentibus flavidis variegatis; pectore flavomaculato; ventre nigro, tenuiter griseo-pubescente, utrinque maculis lateralibus flavidis ornato; femoribus supra apice flavomaculatis; tibiis flavo-annulatis; tarsis flavis articulo ultimo apice nigro. Long. corporis $15-18 \mathrm{~mm}$.

$\widehat{c}$ Antennae corpore fere duplo longiores. Coxae anticae tuberculo brevi obtuso armatae. Femora antica valde incrassata.

Brasilien: Espiritu Santo. - Reichsmuseum in Stockholm.

Eine durch die Färbung leicht kenntliche Art, deren generische Stellung jedoch unsicher ist. Nach Lacordaires Übersicht der Oncideriden-Gattungen gehört die Art zu Jamesia. In dieser Gattung passt sie jedoch nur sehr schlecht und stimmt im Habitus viel besser mit den Ischiocentra- 
Arten überein, von denen sie sich hauptsächlich nur durch die an einander stark genäherten Fühlerhöcker abweicht.

559. Peritrox nigromaculatus n. sp. - Niger; infra griseopubescens, supra et ad latera ochraceo et griseo-variegatus maculisque nigris conspersus; capite fere toto ochraceo, fronte elongata tuberculis antenniferis fere contiguis; antennis corpore longioribus, brunneis, griseo-pubescentibus articulis $3-7$ infra pilosis; prothorace transverso, supra leviter 5-nodoso, utrinque pone medium tuberculo parvo obtuso armato, nodis, tuberculis maculisque utrinque $2-3$ nigris; scutello griseo; elytris fere cylindricis, humeris nudis nitidis nigro-tuberculatis, apice rotundatis inermibus, irregulariter punctatis, punctis apicem versus sensim minoribus, maculis irregularibus nigris undique conspersis; segmentis ventralibus $1-4$ utrinque nigroguttatis. Long. corporis $12-14 \mathrm{~mm}$.

Brasilien: Espiritu Santo; Paraguay. - Reichsmuseum in Stockholm.

Durch den viel kleineren Seitendorn des Halsschildes und die Zeichnung von $P$. denticollis abweichend.

560. Cylicasta virescens n. sp. - Parva, fusca, pube virescente fere omnino tecta, supra punctata, infra fere laevis; antennis corpore plus triplo longioribus, capillaribus, articulis 3-11 fuscis ad basin annulo brevi albido interdum obsoleto ornatis, scapo apice leviter incrassato quam articulo $3^{\circ}$ breviore, articulo $11^{\circ}$ reliquis multo longiore; oculis supra fere contiguis, lobis inferioribus elongato-ovatis quam genis longioribus; prothorace cylindrico, transverso, ad basin levissime constricto; scutello apice rotundato; elytris profunde punctatis maculis irregularibus denudatis fuscis plus minus variegatis, his maculis saepe pone medium fasciam transversam formantibus. Long. corporis $7-9 \mathrm{~mm}$.

Brasilien: Rio Janeiro. - Reichsmuseum in Stockholm.

Diese neue kleine Art weicht von Lacordaires Beschreibung der Gattung nur dadurch ab, dass die Fühler länger sind und ein verhältnismässig kürzeres erstes Glied haben. Das Weibchen ist mir nicht bekannt. Abgeriebene Stücke sehen fast ganz schwarz aus.

561. Hyllisia suturalis n. sp. - Femora postica medium segmenti ventralis secundi attingentia. Elytra apice obtuse 
rotundata. Punctata, brunnea, tomento griseo et ochraceo variegata, prothorace vittis 7 (vitta dorsali laterali in medio leviter incurva), elytris singulis vittis tribus ochraceis; elytris insuper vitta communi suturali ante basin desinente albida; scutello flavo-albido; corpore infra ad latera ochraceo-, in medio grisescente tomentoso; antennis (feminæ?) corpore parum longioribus, ad basin infra pilis perpaucis ciliatis, brunneis, articulis intermediis ad basin plus minus distincte albido-annulatis; scapo fere cylindrico, apicem versus leviter angustato, quam articulo $3^{\circ}$ breviore, articulo $12^{\circ}$ leviter curvato quam penultimo haud longiore. Long. corporis 10 $-12 \mathrm{~mm}$.

Damaraland. - Reichsmuseum in Stockholm. Transvaal: Pretoria-Collectio van Roon.

562. Hippopsis quinquelineata n. sp. - Elongata, sublinearis, elytris apicem versus attenuatis; punctata, vittis flavescentibus, vittis duabus verticis, quinque prothoracis et tribus utrinque elytrorum flavidis, vitta interna elytrorum antice tenuissima vel obsoleta a sutura separata, deinde lata distincta et sutura conjuncta; corpore infra flavo-griseo pubescente, ad latera plus minus distincte vittato; capite elongato quam pronoto vix latiore et parum breviore, fronte valde obliqua supra inter oculos angustata; oculis supra anguste separatis, tuberculis antenniferis fere contiguis; antennis longissimis corpore plus triplo longioribus, brunneis, articulis 1-5 infra sat dense ciliatis, reliquis breviter hirtulis, scapo apicem versus sensim leviter incrassato; prothorace cylindrico vel medio leviter dilatato sparsim punctato; scutello obtuso flavido; elytris apice oblique sinuato-truncatis, angulo suturali brevissime dentato, exteriore in spinam acutam sensim producto; femoribus posticis apicem segmenti $2^{\mathrm{i}}$ fere attingentibus $(\delta)$ vel medium vix superantibus $(q)$; tibiis anticis leviter flexuosis; tibiis posticis maris incrassatis. Long. corporis $10-16 \mathrm{~mm}$.

Südbrasilien. - F. SAHLberG. - Reichsmuseum in Stockholm und Collectio Sahlberg.

Diese Art weicht von allen übrigen südamerikanischen Arten dadurch ab, dass das Halsschild fünf statt sechs hellen Längslinien hat. 
Hippocephala nov. gen.

(Hippopsini).

Caput retractile, infra dilatatum. - Genae longissimae lobis inferioribus oculorum plus duplo longiores. - Oculi mediocres; lobi inferiores rotundati, superiores parvi abbreviati acuminati. - Tuberculi antenniferi suberecti, sulco triangulari angusto separati. - Antennae longissimae, articulo $4^{\circ}$ apicem elytrorum fere attingentes; scapus longus, humeros superans, apice incrassatus, infra dense hirsutus; articulus tertius scapo vix brevior, infra dense ciliatus, reliqui tenuiores parce et breviter ciliati. - Prothorax cylindricus, inermis, subquadratus vel leviter transversus, haud rugosus, apice truncatus, ad basin utrinque emarginatus. - Scutellum latum, transversum, obtuse rotundatum. - Elytra ad basin prothorace multo latiora, supra fere plana, apicem versus sensim angustata, cuneiformia, apice acuminata. - Pedes sat longi; femora sublinearia, postica apicem segmenti ventralis $2^{i}$ attingentia; tibiae anticae intus infra medium leviter incrassatae, intermediae extus sulcatae; tarsi ciliati, antici et intermedii maris deplanati et dilatati, articulus primus laminatus, $2^{\circ}$ et $3^{\circ}$ simul sumtis vix brevior; unguiculi divergentes. Prosternum inter coxas latum, postice valde dilatatum, vix curvatum. - Mesosternum declive, postice apice curvatum et inter coxas leviter emarginatum. - Acetabula antica clausa, extus angulata; intermedia extus aperta.

Diese sehr ausgezeichnete Gattung verbindet mit einander Lacordaires Abteilungen A und B der Hippopsinen und weicht von allen anderen Gattungen durch die vor den Hüften sehr kurze Vorderbrust ab.

563. Hippocephala suturalis n. sp. - Brunneo-flava, infra obscurior, undique pube pallide flava vestita; vertice et pronoto vittis duabus latis fuscescentibus ornatis; elytris linea suturali albida ornatis, circa scutellum plus minus infuscatis. Long. corporis $20-22 \mathrm{~mm}$.

China: Kiukiang (Reichsmuseum in Stockholm); Fokien (Collectio Hauser). 
564. Amphicnaeia cordigera n. sp. - Brunnea vel fusco-brunnea, dense punctata, pube grisea vel flavescentegrisea vestita, vittis duabus dorsalibus sæpe fere contiguis lineaque laterali (interdum obsoleta) prothoracis, area magna cordiformi communi elytrorum circa scutellum interdum linea abbreviata basali utrinque incisa, vitta humerali apicem fere attingente et pone medium in plagam magnam irregularem saepissime dilatata nec non vitta, interdum interrupta, subhumerali elytrorum nudis vel subnudis brunneis: fronte convexa punctata; oculis supra fere contiguis; antennis pedibusque brunneis scapo antennarum et medio femorum plus minus infuscatis; prothorace ad basin leviter angustato; elytris apice singulatim rotundatis. Long. corporis $4,5-5 \mathrm{~mm}$.

Süd-Brasilien: Rio Janeiro. - Reichsmuseum in Stockbolm.

Die Zeichnung der Flügeldecken ist sehr veränderlich, indem die nackten oder fast nackten Längslinien breiter oder schmäler, zusammenhängend oder unterbrochen, gleichbreit oder hinter der Mitte unregelmässig erweitert sind. Der grosse dreieckige oder fast herzförmige Basalfleck ist grösser oder kleiner, fast immer aber durch eine sehr feine weissliche Nahtlinie geteilt und oft jederseits an der Wurzel durch einen kurzen hellen Strich eingeschnitten. Die Pubescenz wechselt von weissgrau bis gelbliçh grau. Die Art scheint häufig zu sein.

Azygocera nov. gen.

Der von Fairmaire und Germain als Zygocera picturata beschriebene Käfer gehört nicht zu den Zygocerinen sondern ist mit Acanthoderes nahe verwandt. Die Stirn ist nämlich nicht nach oben verschmälert und die Fühler an der Wurzel breit getrennt. Die Gelenkhöhlen der Mittelbüften sind, wie bei vielen anderen Acanthoderinen, zwar nicht vollständig, aber doch beinahe geschlossen. Die neue Gattung ist durch folgende Kennzeichen von übrigen Acanthoderinen-Gattungen $\mathrm{zu}$ unterscheiden.

Frons lata, plana, infra leviter dilatata, a genis carina obliqua separata. - Genae longae oculorum lobo inferiore multo longiores. - Oculi subtenue granulati, emarginati (haud 
subdivisi), in fronte latius quam in vertice distantes. - Epistoma distinctum. - Mandibulae mediocres, deplanatae. Antennae ad basin late separatae, corpore parum longiores ( $Q$ ?); scapus pyriformis; articulus $2^{\text {us }}$ elongatus, latitudine apicali plus duplo longior; articulus $3^{\text {us }}$ apice leviter incrassatus et infra dense ciliatus, scapo parum longior, $4^{0}$ distincte brevior; $4^{\text {us }}$ infra apice dense ciliatus; reliqui cylindrici sensim breviores, infra minus dense ciliati. - Prothorax transversus, aequelatus, utrinque spinosus et supra obtuse bituberculatus. - Scutellum apice subtruncatum. - Elytra sat elongata, ad basin declivia, humeris elevato-productis; singulum prope basin tuberculo magno obtuso armatum, apicem versus sensim angustatum et apice obtuse rotundatum, inerme, pone medium costis 2 parum distinctis, apicem haud attingentibus instructum. - Prosternum mediocre, postice leviter arcuatum. - Mesosternum latius, antice subtruncatum, inerme. - Acetabula antica extus valde angulata; intermedia extus fere clausa. - Femora clavata; tarsorum articulus primus $2^{\circ}$ et $3^{\circ}$ simul sumtis parum brevior; tibiae apice modice incrassatae.

Typus: 》Zygocera» picturata FaIrM. \& Germ. (1859).

Die grossen stumpfen Tuberkeln des Halsschildes stehen fast in einer Querlinie mit den Seitendornen.

565. Acanthoderes modesta Gyllenh. - Nachdem ich das typische Stück dieser Art mit Exemplaren von decipiens HALD. verglichen habe, muss ich modesta als ein kleines etwas verbleichtes Weibchen von decipiens erklären. Gyllenhals Typus stammt sicher nicht aus Finnland, sondern wurde wahrscheinlich von KaLM aus Nordamerika heimgebracht und später aus Irrthum als in Finnland gefunden bezeichnet.

566. Probatius quadriguttatus n. sp. - Brunneus, cinereo-pubescens, pronoto pedibusque tenue pubescentibus, elytris setosis subnudis maculis sulphureo-albis conspersis; pronoto guttis 4 sulphureo-albis in linea transversa ante medium positis ornato; scutello summo apice saepe albido; segmentis abdominalibus apice albido-marginatis; segmento dorsali ultimo in utroque sexu apice emarginato et utrinque acute spinoso. Long. corporis $10-14 \mathrm{~mm}$. 
Südbrasilien bis Espiritu Santo. - Reichsmuseum in Stockholm.

Diese in den Sammlungen nicht seltene Art scheint bisher unbeschrieben zu sein. Sie kommt den P. ludicrus und sannio Germ. nahe, weicht aber von beiden sofort durch das Fehlen der hellen Dorsallinie des Halsschildes und die vier hellen Tropfflecke desselben ab. Die hellen Flecke der Flügeldecken sind nach Form und Grösse recht veränderlich; am Seitenrande stehen gewöhnlich nach einander drei grössere, bald unregelmässige, bald fast gerundete Flecke; die Flecke längs der Mitte und an der Naht sind dagegen stets klein und sehr unregelmässig, oft geschlängelt oder strichförmig.

567. Sphenopsilus peruvianus n. sp. - Niger, vertice, pronoto, elytris lateribusque sternorum punctis liturisque parvis flavidis vel cinereis irroratis, infra cum pedibus cinereo-pubescens; antennarum scapo et articulo $3^{\circ}$ longissimis, $4^{\circ}$ annulo latissimo flavescente-albido, $6^{\circ}$ et $8^{\circ}$ ad basin annulo cinereo ornatis; pronoto convexo aequali impunctato, punctis paucis in sulco basali exceptis; scutello apice obtuse rotundato; elytris punctis granulatis distantibus, apicem versus sensim evanescentibus praeditis, pone medium costa parum distincta instructis, apice oblique truncatis angulo suturali dentato, exteriore elongato acuto; pro- et mesosternis declivibus, inermibus. Long. corporis $12-14 \mathrm{~mm}$.

Variat femoribus totis rufis.

ऽ. Antennae longiores articulo $5^{\circ}$ apicem elytrorum fere attingentes. Tibiae anticae apice curvatae, intus in medio dente armatae. Femora praesertim antica valde incrassata. Segmentum ventrale ultimum apicem elytrorum haud attingens, apice emarginatum et utrinque spinosum.

q. Antennae breviores articulo $7^{\circ}$ apicem elytrorum vix attingentes. Tibiae antice rectae, inermes. Femora minus incrassata. Segmentum abdominale ultimum conico-elongatum, apicem elytrorum tamen vix superans, lamina dorsalis lata medio angulata, lamina ventralis emarginata et utrinque spina armata.

Peru. - Reichsmuseum in Stockholm.

Obgleich die Mittelbrust unbewaffnet ist, gehört diese Art ohne Zweifel zu Sphenopsilus. Der Körper ist etwas 
langgestreckter als bei der von Bates gelieferten Abbildung der typischen Art.

\section{Diastosphya nov. gen.}

Frons transversa, vix convexa, inter antennas plana. Genae mediocres. - Oculi late divisi, parvi; lobi inferiores transversi, subtriangulares, genis breviores. - Antennae corpore vix longiores, ad basin late distantes, articulis $11 \mathrm{com}-$ positae; scapus leviter pyriformis articulo $3^{\circ}$ parum longior; articulus $2^{\text {us }}$ elongatus $3^{\circ}$ vix plus quam duplo brevior. Prothorax magnus, basin et apicem versus angustatus, lateribus in medio rotundatis, inermis, latitudine medii vix longior. - Scutellum distinctum, late triangulum. - Elytra capite et prothorace simul sumtis vix longiora, basin versus angustata et ad basin prothorace haud latiora humeris nullis, apicem versus sensim leviter angustata et apice conjunctim rotundata, supra ante medium plana, deinde sensim declivia. - Pedes breves; coxae omnes latissime distantes; femora clavata, brevia; tibiae intermediae extus leviter incisae; acetabula antica rotundata, integra, omnino clausa.

Erinnert durch Körperbau an Odontorhabdus und Haplorhabdus, weicht aber von beiden durch die gegen die Wurzel verschmälerten Flügeldecken (ohne Schulter) ab.

568. Diastosphya fuscicollis n. sp. - Brunnea; capite, prothorace, apice elytrorum, clavis femorum articulisque duabus ultimis antennarum infuscatis vel nigricantibus; elytris fascia subbasali maculisque binis pone medium e pilis adpressis albis formatis; capite et pronoto profunde rude punctatis; elytris subseriatim rude punctatis et postice albidosetulosis; antennis sparsim breviter pilosis, vix autem ciliatis. Long. corporis $3,5 \mathrm{~mm}$.

Fidji Inseln. - Reichsmuseum in Stockbolm.

569. Colobothea peruviana n. sp. - Nigro-fusca, pube tenui grisescente vestita; capite, antennis, pedibus elytrisque rufobrunneis; fronte lineis tribus, vertice duabus postice divergentibus flavidis ornatis; genis longis lobis oculorum inferioribus subaequalibus; antennis maris corpore duplo longioribus infra parce setosis articulo $10^{\circ}$ albido-annulato; 
prothorace leviter conico lateribus omnino rectis, lineis 10 flavis, quarum tribus utrinque dorsalibus, ornato; scutello nigro macula basali flava; elytris macula basali communi circa scutellum plagisque tribus magnis lateralibus atris punctis flavidis circumcinctis ornatis (prima ante medium, secunda paullo pone medium, tertia subapicali suturam non attingentibus), apice truncatis et extus spinosis; sternis abdomineque maculis flavo-albidis ornatis, segmento ultimo ventrali brunneo; pedibus fere unicoloribus; tarsis anticis maris modice dilatatis longe ciliatis. Long. corporis $11 \mathrm{~mm}$.

Peru: Chancamojo, La Mercedes. - Collectio Hauser.

Eine durch die Zeichnung des Halsschildes und der Flügeldecken sehr ausgezeichnete und leicht kenntliche Art.

\section{Glenea Newm.}

Die vielen Arten dieser Gattung scheinen mir in natürlicher Weise auf folgende Gruppen oder Untergattungen verteilt werden zu können.

Übersicht der Untergattungen.

A. Kopf mehr oder weniger zusammengedrückt; die Augen sind von oben gesehen gar nicht hervortretend und bilden darum mit den Schläfen eine gleichmässig und schwach gebogene Linie. Halsschild ganz zylindrisch oder gegen die Wurzel allmählig breiter mit ganz geraden Seiten. Stirn schmal und hoch, besonders bei den Männchen. Die unteren Augenlappen langgestreckt.

Subgenus: Macroglenea. (Typus: G. elegans OLIv.)

B. Kopf nicht zusammengedrückt. Augen mehr oder weniger hervortretend, immer mehr als die Seiten des Kopfes hinter den Augen. Stirn breit.

a. Metasternum nicht gekielt.

* Fühlerschaft nicht oder nur sehr undeutlich gekielt.

Subgenus: Glenea sens. str.

(Typus: G. novemguttata). 
**. Fühlerschaft mit einem deutlichen Kiele, welcher sich von der Wurzel bis zur Spitze erstreckt.

Subgenus: Stiroglenea.

(Typus: G. cantor F.)

३. Metasternum auf jeder Seite vor den Hinterhüften mit einem deutlichen, dicken, schief gestellten Kiele.

Subgenus: Poeciloglenea.

(Typus: G. celia Pasc.)

570. Glenea Nigeriae n. sp. - Parva, brunnea, punctulata, e maxima parte pube densa pallide flavida vel fere straminea, infra albida tecta; antennis brunneis apicem versus infuscatis, scapo nigro; fronte in medio maculis duabus fuscis; prothorace maculis 4 rotundatis nigris, duabus dorsalibus singulaque laterali in linea transversa positis ornato; scutello late rotundato, toto flavido-pubescente; elytris brevibus, subcylindricis, apice truncatis angulo suturali dentiformi, externo spina longa armato, costis humerali et subhumerali ante apicem evanescentibus, parte quinta apicali nitida subnuda atra discrete punctata, vitta laterali a basi ad apicem costarum extensa castanea tenuiter griseo-pubescente, inter suturam et costam humeralem dense flavido-tomentosis vitta basali et macula rotundata discali pone medium fusco-brunneis; corpore infra brunneo-maculato; pedibus totis testaceis; unguiculis appendiculatis. Long. corporis $8,5-9 \mathrm{~mm}$.

Nigeria: Ibadan. - S. African Museum und Reichsmuseum in Stockholm.

Eine leicht kenntliche, durch die Bildung der Klauen abweichende Art. Nur Weibchen liegen mir vor.

571. Glenea Feae n. sp. - Fusco-brunnea, antennis pedibusque nigris, breviter nigro-setosa, elytris totis rufo-brunneis quinta parte apicali griseo-pubescente; pronoto convexo, punctato, linea tenuissima dorsali albida ornato; corpore infra tenue cinerascente pubescente; unguiculis feminae simplicibus. Long. corporis $15 \mathrm{~mm}$.

Fernando Po - L. Fea; 1 o. - Reichsmuseum in Stockholm.

Die Art stimmt in der Körperbildung und der Skulptur mit $G$. balteata überein und ist vielleicht nur eine Abänderung derselben. Wenn man die Flügeldecken mit unbewaffnetem 
Auge betrachtet, kann man eine schwache Andeutung der schwarzen Querbinden von balteata entdecken.

572. Glenea gedeensis. - Fusca; antennis, elytris pedibusque laete brunneis; fronte, genis et corpore subtus viridi pubescentibus; vertice vittis duabus, prothorace vittis 5 elytrisque vittis 7 (plus minus obsoletis) pallide viridibus ornatis; pronoto rude punctato; elytris punctatis, apice oblique emarginatis angulo laterali multo magis producto spinoso, angulo suturali dentato; carina humerali ante apicem evanescente, subhumerali in spinam exeunte. Long. corporis 10 $-13 \mathrm{~mm}$.

Java: Berg Gede. - Fruhstorfer. - Reichsmuseum in Stockholm.

Erinnert etwas an G. strigata Thoms., weicht aber ausser durch die Färbung auch durch die an der Spitze schief ausgerandeten Flügeldecken $\mathrm{ab}$.

573. Glenea nitidicollis n. sp. - Fig. 78. - Olivaceofusca, elytris viridibus ( $\left.\sigma^{\top}\right)$ vel virescentibus ( $q$ ), femoribus ad basin flavescentibus; abdomine sæpe brunnescente vel

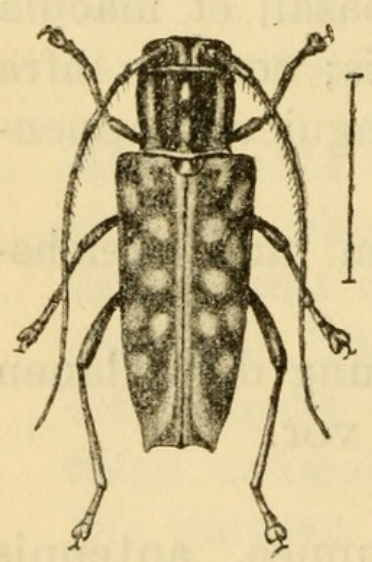

Fig. 78.

Glenea nitidicollis AURIV.

flavido; fronte latitudine multo angustiore, laevi; genis, orbitis oculorum vittisque binis verticis albis $(\hat{0})$ vel ochraceis $(q)$; antennis fuscis obsolete griseo-pubescentibus articulis intermediis maris apice pilo longo tenui in. structis; prothorace nitido supra utrinque punctis perpaucis impresso, vittis 5 albis $(\delta)$ vel ochraceis (o) ornato; scutello apice truncato vel late rotundato et sæpe macula alba vel ochracea ornato; elytris discrete punctatis punctis pone medium evanescentibus, utrinque bicarinatis carinis prope apicem conjunctis et in spinam exeuntibus, maculis 7 rotundatis albis $\left(\delta^{\pi}\right)$ vel ochraceis $(q)$ et in femina insuper macula basali et vitta suturali apice oblique ad spinam lateralem continuata instructis, inter carinas laterales pone humeros saepe vitta brevi ochracea ornatis, apice emarginato-truncatis et bispinosis spina laterali longiore; sternis albido-vel ochraceo-maculatis, ventre annulato. Long. corporis $11-16 \mathrm{~mm}$. 
Sumbawa und Sumatra(?) - Reichsmuseum in Stockholm.

An dem glänzenden Halsschild und der Zeichnung leicht kenntlich.

574. Glenea decemguttata n. sp. - + . Tota cum antennis pedibusque nigra, supra punctata et opaca, infra laevis, nitida, signaturis squamosis viridimetallicis ornata; linea utrinque frontis in vertice continuata, macula magna temporali, vitta lata obliqua utrinque prothoracis postice medium baseos appropinquante, puncto parvo dorsali ad basin et prope apicem, scutello, guttis dorsalibus 5 in singulo elytro $\left(1^{\mathrm{a}}\right.$ discali ante medium, $3^{\mathrm{a}}$ in medio prope suturam, $2^{\mathrm{a}} \cdot 4^{\mathrm{a}}$ et $5^{a}$ lateralibus), gutta in latere deflexo pone humerum strigaque tenui brevi suturali prope apicem, plaga laterali mesosterni, metasterno fere toto, macula magna media segmenti primi abdominis, segmentis $3^{\circ}$ et $4^{\circ}$ totis maculaque utrinque segmenti $5^{\mathrm{i}}$ viridibus; carina humerali elytrorum prope apicem obsoleta cum carina subhumerali in spinam exeunte conjuncta; tarsis brevibus setulosis articulis duabus primis supra virescentibus. Long. corporis $9 \mathrm{~mm}$.

Philippinen. - Museum Bruxellense.

Eine leicht kenntliche Art. Alle nicht grün gefleckten Teile der Unterseite sind glänzend und tief schwarz, nur die Vorderbrust ist etwas matt und vorn an den Seiten punktiert. Die Punkte der Flügeldecken werden nach binten allmählig kleiner.

575. Glenea plagiventris n. sp. - 0 , $q$. A G. anticepunctata, cui valde similis, differt vertice toto (non solum in medio, sed etiam utrinque pone oculos) dense ochraceo tomentoso, pronoto unicolore fusco-brunneo absque vitta, elytrorum parte brunnea basali paullo longiore, macula subapicali longius ab apice distante, puncto ochraceo in sulco laterali adjuncto nec non segmento quarto ventrali utrinque plaga nivea ornato. Long. corporis $10-12 \mathrm{~mm}$.

Java. - Im Brüsseler Museum und Reichsmuseum in Stockholm.

Diese leicht kenntliche Art wurde wahrscheinlich bisher mit anticepunctata verwechselt und stimmt mit dieser auch Arkiv för zoologi Band 13. N:o 9. 
darin überein, dass der Schulterkiel der Flügeldecken sich ganz scharf bis zum Enddorn fortsetzt und an der Spitze mit dem Seitenkiel eine breite Rinne einschliesst. Der untere Schulterkiel ist dagegen an der Spitze ganz verschwunden. Auch bei $G$. Wallacei GAH. sind die Kiele der Flügeldecken in ähnlicher Weise ausgebildet. Bei den in der Färbung ähnlichen $G$. dimidiata F. (udetera Thoms.), aspasia PAsc., semigrisea AurIv., disa Auriv. und theodosia Thoms. geht dagegen der untere Schulterkiel (carina subhumeralis) in den Spitzendorn aus, und der Schulterkiel wird vor der Spitze undeutlich oder vereinigt sich mit dem unteren Kiel.

GaHan führt wohl mit Recht $G$. obsoletepunctata Thомs. und ianthe PASc. als $\delta$ von anticepunctata auf. Da mir aber ein Männchen von anticepunctata vorliegt, welches ganz wie das Weibchen eine ockergelbe Längslinie des Scheitels und des Halsschildes hat, müssen obsoletopunctata und ianthe als Abänderungen des $\delta$ betrachtet werden.

576. Glenea flavovittata n. sp. - $\uparrow$. Nigra vel nigrobrunnea, flavo-vittata; vittis duabus frontis et verticis, genis et temporibus, vittis tribus pronoti, intermedia lata, vittis utrinque binis lateralibus prothoracis antice conjunctis superiore latissima, scutello, vitta suturali et vittis binis (discali et humerali) elytrorum latis et apicem fere attingentibus nec non vitta laterali sterni et abdominis ochraceo-flavis; corpore infra cum pedibus praeterea cinereo-pubescente; carinis lateralibus elytrorum distinctis et postice ante spinam conjunctis; tarsis posticis brevibus articulo primo $2^{\circ}$ et $3^{\circ}$ simul sumtis breviore. Long. corporis $15 \mathrm{~mm}$.

\Kapala, Madang». - Reichsmuseum in Stockholm.

Ich weiss leider nicht sicher, ob dieser Fundort auf Borneo oder anderswo liegt.

577. Glenea bimaculata n. sp. - $\delta$. Brunnea; capite, prothorace, lateribus metasterni, segmento ultimo abdominis, et parte tertia apicali elytrorum nigris vel nigro-fuscis; vitta utrinque frontis et verticis, vitta dorsali et utrinque maculis tribus in serie longitudinali positis pronoti, maculis binis transversis in parte apicali elytrorum nec non vitta lata laterali a genis usque ad apicem abdominis prolongata, in abdomine autem in maculas dissoluta, dense albo-tomentosis; pedibus totis testaceis. Long. corporis $10 \mathrm{~mm}$. 
Philippinen. - Reichsmuseum in Stockholm.

Erinnert sehr an G. relicta PASc. aus Japan. Wie bei dieser vereinigen sich die Seitenkiele der Flügeldecken dicht vor der Spitze. Von relicta unterscheidet sich bimaculata durch hellbraune Fühler, ein längeres, mehr zylindrisches und oben in der Mitte gewölbtes Halsschild, durch weniger tief punktierte Flügeldecken und durch die weissen Zeichnungen.

578. Glenea bangueyensis n. sp. - Brunneo-fusca, infra cinereo-pubescens; macula verticis, dorso toto prothoracis, scutello et vitta lata suturali elytrorum flavo-ochraceo-tomentosis; prothorace utrinque inter colorem ochraceum et cinereum vitta laterali curvata nigra; pedibus flavidis; capite quam thorace latiore inter oculos punctato genis brevibus; prothorace basin versus angustato; carinis lateralibus elytrorum ante apicem in unam conjunctis; lateribus elytrorum subnudis, nitidis. Long. corporis $7 \mathrm{~mm}$.

Insel Bangey an der Nordspitze Borneos. - Reichsmuseum in Stockholm.

579. Glenea latevittata n. sp. - A G. despecta PASc., cui valde affinis, tantum differt vitta dorsali ochracea pronoti latissima basin versus dilatata et scutello plus duplo latiore, vitta laterali prothoracis saepe antice abbreviata antennisque totis nigris vel apice obsolete grisescentibus. Long. corporis $8-13 \mathrm{~mm}$.

Borneo: Kuching and Matang. Mehrere Stücke.

Stirn beim $\delta^{\pi}$ ganz weiss, beim ${ }^{\prime}$ dunkelbraun mit ockergelben Seitenstreifen.

580. Glenea nigrifrons n. sp. - Supra nigrofusca, infra brunnea et dense albido-tomentosa; capite fusco, temporibus, genis vittaque utrinque frontis albidis; antennis fuscis; pronoto laete fulvo fascia transversa basali quartam partem longitudinis occupante et margine apicali nigris, lateribus totis albidis; scutello toto fusco; elytris immaculatis fuscis pube tenui brunneo-sericeo vestitis; mesosterno (episternis et epimeris dense albido-tomentosis exceptis), plaga media metasterni et vitta media abdominis subnudis; pedibus totis pallide brunneis tibiis apice leviter infuscatis. Long. corporis $16 \mathrm{~mm}$. 
Borneo: Kuching.

Stimmt mit G. erythrodera GAH. aus Sumatra durch das schwarze Querband an der Wurzel des Halsschildes, weicht aber durch die dicht weiss tomentierten Seiten des Hinterleibes und die in der Mitte schwarze Stirn ab. Von der folgenden Art weicht sie durch die Färbung der Stirn, des Halsschildes und der Beine ab.

581. Glenea rufifrons n. sp. - Supra nigrofusca, infra fusca vel fuscobrunnea et tomento denso albido vestita; fronte, vitta lata verticis, dorso et dimidio superiore laterum prothoracis scutelloque tomento laete rufo vestitis; elytris unicoloribus nigris pube tenuissima glaucescente vestitis; antennis pedibusqe nigrofuscis, femoribus ad basin testa-

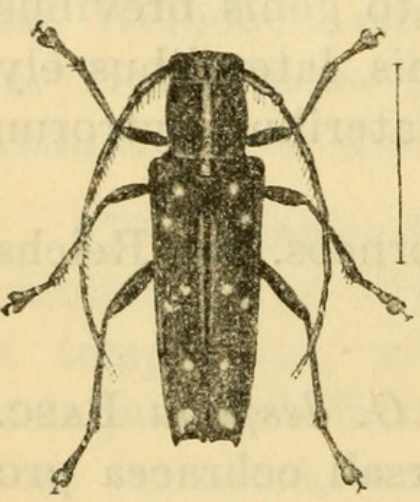

Fig. 79. Glenea vittulata Auriv. ceis; mesosterno cum episternis, area media metasterni vittaque lata media abdominis subnudis fuscis pube tenui grisea vestitis; capite et prothorace vix punctatis, elytris sat fortiter subseriatim punctatis. Long. corporis $14-18 \mathrm{~mm}$.

Borneo: Kuching und Matang. $-2 \delta \delta^{\top}$, 2 q $q$.

Offenbar mit $G$. ruficollis GaH. nahe verwandt; aber dadurch verschieden, dass der Scheitel einen roten Streif hat, dass die Schenkel an der Wurzel gelb sind und dass die Seiten des Halsschildes oben rot, unten weiss (nicht braun) sind. Die Fussklauen sind bei beiden Geschlechtern einfach.

582. Glenea vittulata n. sp. -- Fig. 79. - Brunneo-vel nigro-fusca, infra pube densa nivea vestita, supra subnuda vittis et maculis vel punctis pallidis ornata, punctata; fronte latitudine altiore utrinque vitta ochracea ornata; vertice bivittato; prothorace vitta singula dorsali ochracea et utrinque vitta laterali alba ornato; scutello macula apicali ochracea; elytris ad carinam humeralem fortius punctatis, carina humerali usque ad apicem acuta et distincta in spinam apicalem exeunte, carina subhumerali obsoleta ante apicem evanescente, singulis punctis 5 dorsalibus et macula subapicali albo-pubescentibus ornatis, puncto primo in disco pone basin, secundo laterali ante medium, tertio discali et quarto laterali 
paullulo pone medium sitis, illo ad basin paullo magis appropinquata, quinto prope suturam fere in medio inter apicem et quartam, linea albida suturali nec basin nec apicem attingente; pedibus fusco-brunneis, femoribus ad basin pallidioribus, tarsis fuscis griseo pubescentibus. Long. corporis $13 \mathrm{~mm}$.

Borneo. - Reichsmuseum in Stockholm.

Mit $G$. adelia nahe verwandt.

583. Daphisia guttata n. sp. - Brunnea, tomento niveo vestita; antennis nigris; pedibus testaceis tarsis infuscatis; fronte fusea utrinque albo-vittata, genis et temporibus albis; vertice vittis duabus latis albis contiguis ornato; prothorace albo vittis duabus dorsalibus maculaque laterali subnudis nigrofuscis; scutello albo; elytris brunneis guttis quaternis albis (prima discali prope basin, secunda marginali ante medium, tertia marginali pone medium et quarta parva ante apicem) ornatis et apice ipso cinerascentibus, apice suboblique truncatis et extus breviter dentatis. Long. corporis $12 \mathrm{~mm}$.

Kuching. - 10 .

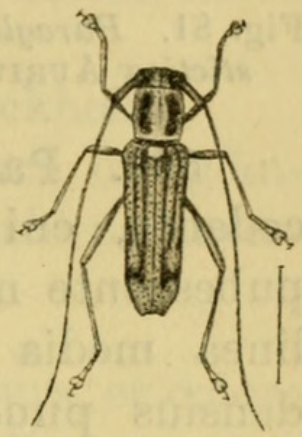

Fig. 80. Daphisia vittata AURIV.

584. Daphisia vittata n. sp. - Fig. 80. - ․ Brunnea, infra tomento denso cretaceo undique tecta; pedibus testaceis; fronte lata, punctata, pube cinereo-albida vestita; vertice obsolete albido-bivittato; prothorace macula utrinque laterali et vittis duabus latis dorsalibus nec basin nec apicem attingentibus nigris; scutello lato albo; elytris fusco-brunneis, punctulatis, vitta suturali vittisque binis nec basin nec apicem. attingentibus maculaque apicali albidis, vitta externa postice in maculam elongatam dilatata; tarsis brevibus niveis. Long. corporis $8 \mathrm{~mm}$.

Borneo; Kuching. - Reichsmuseum in Stockbolm.

585. Paraglenea stictica n. sp. - Fig. 81. - Nigra, elytris obscure brunneis; infra cinereo-pubescens, vitta angusta laterali metasterni maculisque lateralibus abdominis albo-tomentosis; vittis duabus verticis, tribus pronoti (intermedia latiore), scutello, lineis 3 maculisque 3 singuli elytri albido vel ochraceo tomentosis, linea suturali tenuissima, 
discali ante medium, humerali pone medium abbreviata; macula prima discali in medio subtransversa, secunda laterali pone apicem lineae humeralis, tertia elongata fere apicali;

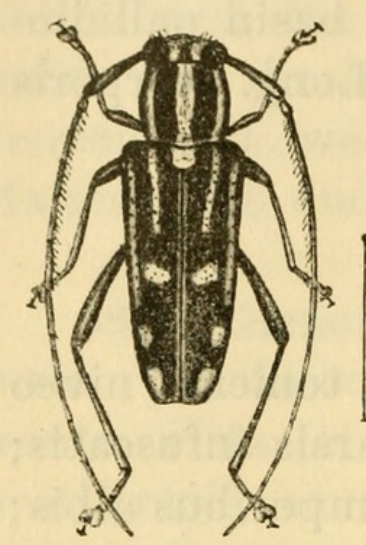

Fig. 81. Paraglenea stictica AURIV. antennis brunneis, scapo cinereo pubescente, articulo tertio valde elongato, quam $4^{\circ}$ plus duplo longiore, albido; pedibus testaceis aut brunneis, femoribus ad basin pallidioribus; tarsis albidis; elytris usque ad apicem rude punctatis, apice leviter truncatis inermibus carinis ante apicem evanescentibus. Long. corporis $12 \mathrm{~mm}$.

Tonkin: auf dem Mauson-Berge; 2-3,000 m. - Reichsmuseum in Stockholm.

586. Paraglenea monticola n. sp. - ․․ A specie praecedente, cui valde affinis, corpore infra undique cinereopubescente maculis albidis nullis, vittis pronoti angustioribus, linea media scutelli tantum alba, elytris adbuc fortius et densius punctatis, nigricantibus, vitta suturali et utrinque tribus (discali, humerali et subhumerali) griseo-albidis apicem fere attingentibus ornatis, nec non articulo tertio antennarum breviore differt. Long. corporis $12 \mathrm{~mm}$.

Tonkin: Mauson Berge; 2-3,000 m. - Reichsmuseum in Stockholm.

Die helle Diskallinie der Flügeldecken ist in der Mitte sehr fein, fast unterbrochen, und dann zu einem kleinen Punkt entwickelt und an der Spitze wieder etwas verbreitet. Die Schulterlinie ist bedeutend länger als bei $P$. stictica ohne jedoch die Spitze zu erreichen und ohne Erweiterung an der Spitze. Das erste Glied der Hintertarsen scheint etwas kürzer als bei stictica $\mathrm{zu}$ sein und kaum so lang wie das zweite und dritte Glied zusammengenommen. Die Seitenkiele der Flügeldecken sind bei beiden Arten gut entwickelt, verschwinden aber völlig ziemlich weit vor der Spitze.

587. Nupserha tricolor n. sp. - Pallide flavida, elytris nigris fascia angusta basali pone humeros paullulum dilatata flava parteque quarta vel quinta apicali flavo-brunnea; puncto frontis inter antennas, puncto verticis punctisque 4 prothoracis (2 dorsalibus, 2 lateralibus) nigris; dorso abdo- 
minis nigricante; summo apice tibiarum extus tarsisque plus minus infuscatis; antennarum articulis $1-5$ plus minus flavidis apice nigris, vel scapo et tertio fere totis nigris, 6-11 cinereofuscis: Long. corporis $9-11 \mathrm{~mm}$.

Kamerun: Joko. - Reichsmúseum in Stockholm.

Schliesst sich der $N$. basalis ER. an, weicht aber durch den unten einfarbig gelben Hinterkörper, die an der Wurzel hell gefärbten Fühler, die sehr schmale Wurzelbinde und den braunen Apicalteil der Flügeldecken ab.

588. Hecphora nitida n. sp. - Ferruginea, nitida, oculis et antennarum articulis 6-11 tantum nigris, articulo $5^{\circ}$ apice plus minus infuscato; processu pronoti magno antice fovea maxima impresso. Long. corporis $11 \mathrm{~mm}$.

Kamerun. - 1 우. - Reichsmuseum in Stockholm.

Der H. testator F. sehr ähnlich, aber durch die glänzendere Oberseite und die Färbung der Fühler leicht zu unterscheiden.

589. Hecphora simplicicollis n. sp. - Statura et colore speciei praecedenti omnino similis, ab omnibus adhuc cognitis speciebus generis Hecphorae autem processu dorsali pronoti omnino deficiente mox distincta. Ferruginea, nitida, longius pilosa, oculis, articulis $6-11$ antennarum apiceque mandibularum nigris; capite sparsim punctato fronte inter antennas fere omnino plana; prothorace transverso, utrinque in medio obtuse carinato-tuberculato, sulcis transversis utrinque profundis, anteriore supra obsoleta, posteriore supra in medio recurva et angustata, margine basali in medio elevata, tenui, vitta dorsali media laevi impunctata, dorso utrinque sparsim punctato; elytris punctatis, nitidis, pilosis, apice inermibus; segmento ultimo ventrali feminæ medio canaliculato et utrinque prope marginem impresso. Long. corporis $11-12 \mathrm{~mm}$.

Kamerun. - 1 ․ - Reichsmuseum in Stockholm.

Die Bildung des Halsschildes stimmt mit derjenigen vieler Astathes-Arten nahe überein; die Mitte des Rückens ist jedoch nicht pyramidenförmig, sondern flach und nur nach hinten ein wenig erhöht.

590. Amphionycha brunneiceps n. sp. - Brunnea, tomento denso cretaceo vestita; capite, vitta latissima dorsali pronoti scutelloque obscure cinnamomeis; antennis brunneis, 
scapo obscuro cinnamomeo; pedibus pallide testaceis, tarsis albidis; ventre vitta angusta media, subnuda, brunnea ornato; capite magno prothorace latiore, adpresse piloso, impunctato; fronte latissima subquadrata, inter antennas leviter excavata; oculis ruaje granulatis, lobis inferioribus magnis quadratis quam genis duplo longioribus, antennis maris corpore parum longioribus, articulis $1-8$ infra ciliatis; articulo $3^{\circ}$ scapo multo longiore; scapo et articulo $4^{0}$ subæqualibus; prothorace fere omnino cylindrico, basin versus vix angustato, vitta dorsali rude punctata utrinque inæqualiter limitata et prope medium pube cretacea indentata; scutello magno postice obtuse rotundato; elytris ad basin subrecte truncatis, pronoto multo latioribus, apicem versus sensim angustatis apice subacute rotundatis inermibus, utrinque carina laterali, simplice acuta nuda instructis; segmento ventrali ultimo maris apice inciso. Long. corporis $19 \mathrm{~mm}$,

Brasilien: Rio Janeiro. - $1 \delta$. Reichsmuseum in Stockholm.

Eine durch die einfarbigen kreideweissen Flügeldecken und den dunklen Kopf sehr leicht kenntliche Art.

\section{Pseudomecas gen. nov. Aerenicinarum.}

Corpus lineare, elongatum. - Caput latum, breve, pone oculos constrictum; frons latitudine altior, sat angusta, suhparallela, inter antennas modice concava. - Oculi magni, rude granulati; lobi inferiores maximi valde tumidi; genae brevissimae. - Antennae corpore plus quinta parte longiores; scapus elongato-obconicus, basin pronoti fere attingens, articulo tertio multo longior; articulus $4^{\text {us }}$ tertio paullo longior; articuli 1-6 infra ciliati. - Prothorax cylinảricus, latitudine multo longior, utrinque ante medium leviter constrictus, inermis. - Scutellum subquadratum, apice fere truncatum. Elytra elongata, linearia, ad basin truncata et pronoto multo latiora, apice singulatim acuminato-rotundata et spina brevissima armata, lateraliter rotundato-declivia, haud carinata. - Coxae.anticæ anguste, intermediæ latius distantes. - Acetabula antica clausa; intermedia extus anguste aperta. Pedes breves; femora postica apicem segmenti ventralis secundæ haud attingentia; tibiæ anticæ et intermediæ apice 
plus minus curvatae. - Tarsi elongati; articulus basalis posticorum reliquis simul sumtis vix brevior. - Unguiculi fissi. - Episterna metathoracalia valde elongata linearia.

Diese ohne Zweifel mit Aerenica und Antodyce verwandte Gattung erinnert an die nordamerikanische Gattung Mecas, weicht aber von dieser durch die Bildung der Klauen, der Episternen der Hinterbrust und der Spitze der Flügeldecken ab.

591. Pseudomecas femoralis n. sp. - Angusta, linearis, nigra undique tomento denso griseo-cano vestita; femoribus basique tibiarum rufotestaceis; tibiarum apice tarsisque nigris; antennis fuscis scapo nigricante. Long. corporis $10-13 \mathrm{~mm}$.

Argentina: Chaco de Santiago (WAGNER). - Reichsmuseum in Stockholm.

592. Nyctonympha flavipes n. sp. - Brunneo-fusca, tenue griseo-pubescens, pronoto linea dorsali densius pubescente; capite et prothorace profunde discrete punctatis; antennis corpore parum longioribus, fuscis articulis $4-11$ ad basin anguste albido-annulatis, articulo $4^{\circ}$ quam $3^{\circ}$ fere duplo longiore; prothorace fere cylindrico utrinque dente parvo acuto armato; scutello apice truncato; elytris elongatis supra subplanis, apicem versus sensim angustatis, apice oblique emarginatis et bidentatis (dente suturali minuto, externo valido) subseriatim punctatis seriebus 4 internis fere regularibus; metasterno utrinque punctato; pedibus laevibus flavidis femoribus tibiisque in medio annulo fusco ornatis. Long. corporis 8 mill.

Bolivia: Mapiri. - Reichsmuseum in Stockholm.

593. Nyctonympha rufipes n. sp. - Nigra, pedibus rufis: pube cinerea sat densa undique vestita; capite et prothorace sat dense, minus fortiter punctatis punctis vestitura plus minus obtectis; antennis longis articulo $7^{\circ}$ apicem elytrorum attingentibus, infra ciliatis, unicoloribus nigris, articulo $4^{\circ}$ quam $3^{\circ}$ multo longiore; prothorace cylindrico inermi; elytris sublinearibus, apice oblique rotundato-truncatis angulo exteriore dentato, seriato-punctatis interstitiis subelevatis, punctis summo apice irregulariter sparsis; tibiis posticis infuscatis. Long. corporis $8-8,5 \mathrm{~mm}$.

Arkiv för zoologi. Bd 13. N:o 9. 
Brasilien: Theresopolis (F. Schneider). - Reichsmuseum in Stockholm und Collectio van Roon.

594. Nyctonympha setulosa n. sp. - Elongata subparallela, brunnea antennis pedibusque pallidioribus; tenuissime griseo-pubescens et ad apicem elytrorum setulosa; capite prothoraceque dense et profunde subrugoso-punctatis; antennis corpore vix longioribus brunneis articulis $1-4$ unicoloribus, $4^{\circ}$ quam $3^{\circ}$ parum longiore, $5-11$ ad basin sat late pallide annulatis; prothorace cylindrico, inermi, supra apicem versus magis convexo; elytris punctato-striatis interstitio $5^{\circ}$ costulato granulisque paucis minutis obsito, apice oblique emarginato-truncatis angulo suturali spina brevi, externo spina longiore armato; pectore abdomineque sparsim punctatis; pedibus rufobrunneis, femoribus in medio infuscatis. Long. corporis $10 \mathrm{~mm}$.

Brasilien: Rio Janeiro. - Reichsmuseum in Stockholm.

Die bisher beschriebenen Arten der Gattung Nyctonympha können nach folgender Übersicht leicht unterschieden werden. Die typische Art, $N$. cribrata Thомs., ist mir nur durch die Beschreibung Thomson's bekannt.

\section{Conspectus specierum.}

I. Prothorax utrinque tuberculo minuto armatus.

A. Antennae unicolores brunneae. Femora fusca.

B. Antennae pallide annulatae.

1. N. cribrata.

a. Antennarum articulus tertius unicolor, haud annulatus.

1. Antennarum articuli $4-11$ ad basin brevissime albido-annulati. Pedes pallide flavi; femora et tibiæ in medio cingulo fusco cincta.

2. $N$. flavipes.

2. Antennarum articuli 4-11 latius annulati, $10^{\text {us }}$ et $11^{\text {us }}$ apice excepto flavi. Pedes concolores obscuri.

3. N. glauca.

$\beta$. Antennarum articulus tertius, ut etiam articuli 4-11, ad basin late flavo-annulatus. Pedes obscuri; tibiæ ad basin pallidae.

4. N. annulata. 
II. Prothorax omnino inermis.

A. Antennae nigrae, haud annulatae; articulus tertius $4^{\circ}$ multo longior. Pedes rufi.

5. N. rufipes.

B. Antennae brunneae; articuli $5-11$ ad basin pallidiores; articulus tertius $4^{\circ}$ parum longior.

6. N. setulosa.

595. Prosopocera quadripunctata n. sp. $-\delta$. Robusta, brevis, fusca, pube fusco-brunnea, in elytris postice obsolete griseo-variegata undique vestita; vitta latissima laterali prosterni et mesosterni nec non plaga laterali bene definita elytrorum albido-tomentosis; plagis elytrorum ad marginen anticum maculis binis rotundis nigris ornatis; oculis ciliis albidis cinctis; cornu frontali valido brevi, apice bifido; antennis corpore fere duplo longioribus, articulo $3^{\circ}$ scapo parum longiore, sequentibus sensim longioribus; prothorace utrinque spina obtusa sat longa et valida ornato, pronoto in medio inæquali elevationibus distincte rugosis; elytris latis brevibus, ad basin, præsertim pone humeros, granulatis, deinde sparsim punctatis, apice rotundatis, inermibus; mesosterno oblique valde tuberculato-producto, postice canaliculato. Long. corporis $22 \mathrm{~mm}$., lat. ad humeros $10 \mathrm{~mm}$.

Belgisch Kongo: Kingoye. - E. Laman.

Erinnert an $P$. bipunctata DrURy, ist aber kürzer und breiter und sofort dadurch zu unterscheiden, dass der weisse Seitenfleck der Flügeldecken zwei schwarze Punktflecke, statt des einzigen viel grösseren schwarzen Fleckes bei bipunctata, hat.

Tryckt den 6 september 1920.

Uppsala 1920. Almqvist \& Wiksells Boktryckeri-A.-B. 


\section{$2 \mathrm{BHL}$ Biodiversity Heritage Library}

Aurivillius, Carl Wilhelm Samuel. 1920. "Neue oder wenig bekannte Coleoptera Longicornia. 17." Arkiv för zoologi 13, 1-43.

https://doi.org/10.5962/bhl.part.20147.

View This Item Online: https://www.biodiversitylibrary.org/item/30139

DOI: https://doi.org/10.5962/bhl.part.20147

Permalink: https://www.biodiversitylibrary.org/partpdf/20147

\section{Holding Institution}

MBLWHOI Library

Sponsored by

MBLWHOI Library

\section{Copyright \& Reuse}

Copyright Status: NOT_IN_COPYRIGHT

This document was created from content at the Biodiversity Heritage Library, the world's largest open access digital library for biodiversity literature and archives. Visit BHL at https://www.biodiversitylibrary.org. 